\title{
Integrated Decision-Support Methodology for Combined Centralized- Decentralized Waste-to-Energy Management Systems Design
}

\begin{abstract}
The rapid expansion of urban populations and concomitant increase in the generation of municipal solid waste (MSW) exert considerable pressure on the conventional centralized MSW management system and are beginning to exceed disposal capacities. To tackle this issue, the conventional centralized MSW management system is more likely to evolve toward a more decentralized system with smaller capacity waste treatment facilities that are integrated at different levels of the urban environment, e.g., buildings, districts, and municipalities. In addition, MSW can become an important urban resource to address the rising energy consumption through waste-to-energy (WTE) technologies capable of generating electricity, heat, and biogas. This shift toward the combined centralized-decentralized waste-to-energy management system (WtEMS) requires an adapted decision-support methodology (DSM) that can assist decision-makers in analyzing MSW generation across large urban territories and designing optimal long-term WtEMS.

The proposed integrated DSM for WtEMS planning relies on: i) an MSW segregation and prediction methodology, ii) an optimization methodology for the deployment of multi-level urban waste infrastructure combining centralized and decentralized facilities, and iii) a multicriterion sustainability framework for WtEMS assessment. The proposed DSM was tested on a case study that was located in Singapore. The proposed WtEMS not only reduced the total operational expenses by about $50 \%$, but also increased revenues from electricity recovery by two times in comparison with the conventional MSW management system. It also allowed more optimal land use (capacity-land fragmentation was reduced by 74.8\%) and reduced the size of the required transportation fleet by $15.3 \%$ in comparison with the conventional MSW system. The Global Warming Potential (GWP) was improved by about 18.7\%.
\end{abstract}

Keywords: mega-cities, municipal solid waste, waste-to-energy, combined centralizeddecentralized management systems, waste sources segregation, long-term planning

Nomenclature

Abbreviations

MSW - Municipal Solid Waste

WtE - Waste-to-Energy

WtEMS - Waste-to-Energy Management System

LCA - Life Cycle Analysis

DSM - Decision Support Methodology

DF - Decentralized Facility

$\mathrm{CF}-$ Centralized Facility 
WGS - Waste Generation Source

WTF - Waste Treatment Facility

DF - Decentralized Facility

CF - Centralized Facility

KPI - Key Performance Indicator

GWP - Global Warming Potential

\section{Sets}

$|T|, t \in T$ - Life span period of a WTF [year]

$|I|, i \in I-$ Number of waste generators [unit]

$|J|, j \in J$ - Number of candidate sites where decentralized (on-site) and centralized (off-site) treatment facilities can be installed [unit]

$|A|, a \in A-$ Set of technologies available for the deployment

$|L|, l \in L-$ Possible number of units of each technology that can be deployed at each candidate site [unit]

\section{Parameters and variables}

$q_{i, t^{-}}$Amount of waste generated at each time step, $t$, by each waste generator, $i$ [tons of waste/year]

$k_{a^{-}}^{0}$ Unit transformation capacity of treatment facility [tons of processed waste/day]

$K_{a, j}$ - Limitation of land space represented by the maximum number of units of technology, $a$, to be installed at candidate site, $j$ [units]

$\lambda_{a, r^{-}}^{0}$-Amount of recovered resource per ton of treated waste of technology, $a$ [Amount of recovered energy/material/ton of processed waste]

$m_{a, r}^{0}-$ Amount of additional resources, i.e., water and electricity, required for one ton of waste treatment by technology, $a$ [amount of consumed resource/ton of treated waste]

$k^{2}$ - Amount of waste which can be transported by one transportation unit (e.g., a truck) [tons of waste/transportation unit]

$D_{i, j}$ - Distance between a waste generator, $i$,and candidate site, $j[\mathrm{~km}]$

$c_{a, l}^{0}-$ Waste treatment facility deployment cost for the technology, $a$, and unit, $l$, per one-ton capacity [\$/unit capacity] 
$c^{1}-$ Cost associated with waste transportation per kilometer $[\$ / \mathrm{km}]$

$c_{a}^{2}-$ Operations cost of technology, $a$, including facilities maintenance and other possible expenditures, e.g., lease costs for treatment machines [\$/unit capacity]

$c_{l, a, j}^{3}$ - Cost associated with land use required for waste treatment unit, $l$, of technology, $a$, at each candidate site, $j[\$ /$ unit capacity]

$c_{l, a}^{4}$ - Manpower cost depending on type of technology, $a$, and number of installed units, $l$ [\$/unit capacity]

$c^{5}-\mathrm{CO}_{2}$ penalties or taxes associated with waste transportation and treatment $\left[\$ /\right.$ ton of $\mathrm{CO}_{2}$ equivalent]

$p_{r}^{0}-$ Resources price for resource consumption or recovery during waste treatment process [\$/amount of energy/material]

$e_{a}^{0}-$ Emissions per ton of treated waste $\left[\mathrm{gCO}_{2}\right.$ equivalent/ton of processed waste]

$e^{1}-$ Emissions per $\mathrm{km}$ of waste transportation $\left[\mathrm{gCO}_{2}\right.$ equivalent $\left./ \mathrm{km}\right]$

$r$ - Discount rate

$z_{a, l^{-}}$The coefficient for cost reduction for every subsequent unit, $l$, of technology, $a$

$E o S_{a}-$ Economy of Scale factor

$M$ - Arbitrarily large number

$x_{a, j, l, t}-$ Decision variable indicating the number of capacity units, $l$, of technology type, $a$, to be deployed at candidate site, $j$, at time step, $t$

$y_{a, i, j, t}-$ Decision variable indicating the amount of waste generated by waste generator, $i$, assigned (i.e., transported) to the technology of type, $a$, installed at candidate site, $j$, at time step, $t$

$u_{t}^{+}, u_{t}^{-}$- Additional continuous variables to determine the smaller value between the quantity of waste, $q_{i, t}$, generated at WGS $i$ at time step tis greater than or equal to the system capacity, $x_{j, l, t}$, installed at candidate site, $j$

$v_{t}-$ Binary decision variable, equal to 1 if the quantity of the waste, $q_{i, t}$, generated at WGS $i$ at time step, $t$, is greater than or equal to the system capacity, $x_{j, l, t}$, installed at candidate site, $j$

\section{Introduction}

Over the past decades, the global urban population increased significantly, has reached 3.9 billion residents, and is projected to increase $66 \%$ by 2050 [1]. The disparity between urban and rural populations will become drastic for some regions, with about $90 \%$ of the population living in cities and driving the creation of large mega-cities [1]. Continuous urbanization 
amplifies challenges related to the adequate delivery of basic services and infrastructure to ensure a minimum quality of life for the residents [2]. One of these challenges concerns the efficient management of municipal solid waste (MSW), the amount of which is expected to increase from 1.3 billion tons per year in 2012 to almost 2.2 billion tons per year in 2025 [3].

Classical strategies for MSW management rely on incineration, sanitary landfills, and open dumps. For Organisation for Economic Co-operation and Development (OECD) countries, incineration covered $21 \%$ of waste, whereas sanitary landfills hosted more than $42 \%$ of MSW generated in 2012 [3]. In AFR countries, $78 \%$ was sent to open dumps and $88 \%$ was landfilled [3].

More recently, several countries started their journeys toward more responsible MSW management, with an emphasis on increasing resource recovery and decreasing waste disposal. Countries with modest land territories showed exemplary results in achieving waste management goals by transforming their disposal space shortage bottleneck into a driver for the deployment of sustainable MSW management. Japan went under an $11 \%$ threshold of MSW disposal rates by promoting new waste management incentives starting in 1970 [4]. South Korea decreased its landfill rate from over $90 \%$ in the 1980 s to under $10 \%$, while its recycling rate increased to $80 \%$ [5]. Germany reduced the number of landfill sites from 50,000 in 1950 to 300 in 2016, and is planning to recommission all remaining landfills by 2022 [6]. Belgium is regarded as one of the top performers in waste management, with $75 \%$ of its waste being reused, recycled, or composted. This resulted from the implementation of waste management plans that were crafted 25 years ago [6].

At the same time, the reliance on centralized MSW management architecture has been proven to be inefficient by many scholars based on the experience of other countries. The increasing MSW amounts require the expansion of the waste collection fleets and extension of transportation journeys that contribute to traffic jams [7], local pollution, and road deterioration [8]. Increasing MSW amounts also stimulate the deployment of new large disposal and incineration facilities to replace the existing ones whose capacities are being rapidly exceeded [9]. These factors make centralized MSW management expensive and unsustainable in practice, which can also decrease the resilience of cities and amplify risks related to public health and the environment [2]. The option of shrinking large disposal capacities has been recognized to be an important world concern in the face of rapid urbanization [10] (Figure 1(a)).

Various waste recycling technologies and initiatives have been adopted as alternatives to the classical centralized strategies for waste disposal. Indeed, by considering MSW as a valuable resource, new recycling technologies can generate electricity and useful heat [11], syngas and biodiesel [12], compost and liquid fertilizer [13], and other by-products. In some cases, waste becomes an important alternative to address resource scarcity, e.g., waste-to-energy (WtE) technologies that can generate electricity, heat, and biogas. Such technologies have been considered in different countries to overcome energy production scarcity issues [14], [15]. To enable this multi-resource recovery, the classical approach to MSW management that consists of large centralized plants located in the city periphery is more likely to evolve towards a management system with waste treatment facilities of smaller capacity integrated directly into the urban environment [11] (Figure 1(b)). On one hand, this decentralization of waste treatment will ensure the minimization of waste collection areas, transportation distances, and requirements for the transportation fleet by treating MSW at a site closer to waste generation sources (WGS) and recovering valuable resources closer to the final consumers. On the other 
hand, this decentralization will relieve the pressure on existing centralized landfill infrastructures. This new combined waste management system will become integral to the city metabolism that is aimed at eliminating waste and pollution resulting from residents, municipal activities, and businesses. An urban-integrated MSW management framework will further contribute to mitigating climate change. A relatively modest effort toward waste source segregation and recovery can lead to a considerable environmental improvement [16] and even conversion of the waste management system into a carbon sink [17].

While a wide range of waste management planning tools [18] and, more specifically, decisionsupport tools [19] exists, they are not adapted for current planning conditions and may not always accommodate planners' concerns. Indeed, a better understanding of the factors related to multi-level centralized and decentralized waste treatment, resource recovery, and associated economic outcomes are required in modern planning tools. Additional considerations include extended environmental, social, and urban planning constraints (e.g., available land and transportation limitations) and clear solution benchmarking. This is confirmed by the ongoing international initiatives for the development of digital and data-driven management systems, e.g., in Amsterdam [20] and Singapore [21].

A decision-support methodology (DSM) is required to establish a more systematic long-term system planning approach that capitalizes on the examples of the foremost countries in terms of implementing MSW management strategies. The DSM must allow a successful transfer of MSW management practices between counties, while considering local peculiarities and constraints. Extensive work is still required for the development of coherent MSW management solutions in an urban context in the presence of multiple stakeholders and decision factors [16]. Thus, the focus of this paper is on the development of a novel DSM for MSW recycling that is consistent with this analysis and the hierarchy of MSW management measures defined by DIRECTIVE 2008/98/EC [22].

A detailed review of these recent advancements and their bottlenecks is provided in Section 7. In response to these bottlenecks, the paper addresses the issue of establishing a sustainable WtEMS urban architecture based on MSW source territorial distribution. It does so by developing a novel integrated DSM with a demonstration application and contributions along the following three pillars:

(i) It makes an important advancement toward segregation of MSW sources and modeling of their distribution across large urban territories. The proposed approach explicitly defines the relationship between MSW generation and explanatory variables based on different urban activities and their intensity across large urban territories. This approach requires neither the collection of large data amounts nor extended surveys. In addition, it provides MSW estimations depending on the evolution of the urban landscape defined by urban planners.

(ii) It proposes a methodology for WtEMS design optimization that considers multilevel candidate locations (e.g., at the level of buildings, districts, and global cities) for facilities combining various treatment technologies of different capacities. In addition, it takes into account not only specific urban-planning constraints in transportation flows (when waste can be transported only to one treatment site) but also limitations in land-space occupation. The proposed methodology provides the optimization schedule for MSW treatment facilities deployment over a large 
planning horizon, alongside optimal waste assignment (i.e., transportation schedule) for different time periods.

(iii)It provides an extended multi-criteria framework as an additional filter to evaluate the compliance of the WtEMS design with economic, environmental, and social indicators. This evaluation method avoids the complexity arising from multiobjective optimization accounting for these factors.

The proposed integrated methodology provides guidance to decision-makers to identify WtEMS with an optimal balance between centralized and decentralized facilities by selecting optimal technologies, their locations, capacities, and waste assignment. A tractable optimization model provides an optimal solution for decision-makers in a reasonable time and illustrates the trade-off between economic, environmental, and social factors.

The remaining sections of the paper are organized as follows. Section 7 provides an extensive literature review related to the three key research pillars for sustainable WtEMS and analyses existing bottlenecks. Section 11 outlines an integrated DSM for sustainable planning of combined centralized-decentralized WtEMS. In Section 24, the methodology is applied to the analysis of a Singapore case study as an illustration. In Section 38, a critical analysis of the proposed methodology is provided and future research directions are identified. Section 38 concludes with a synthesis and discussion of the main research outputs.

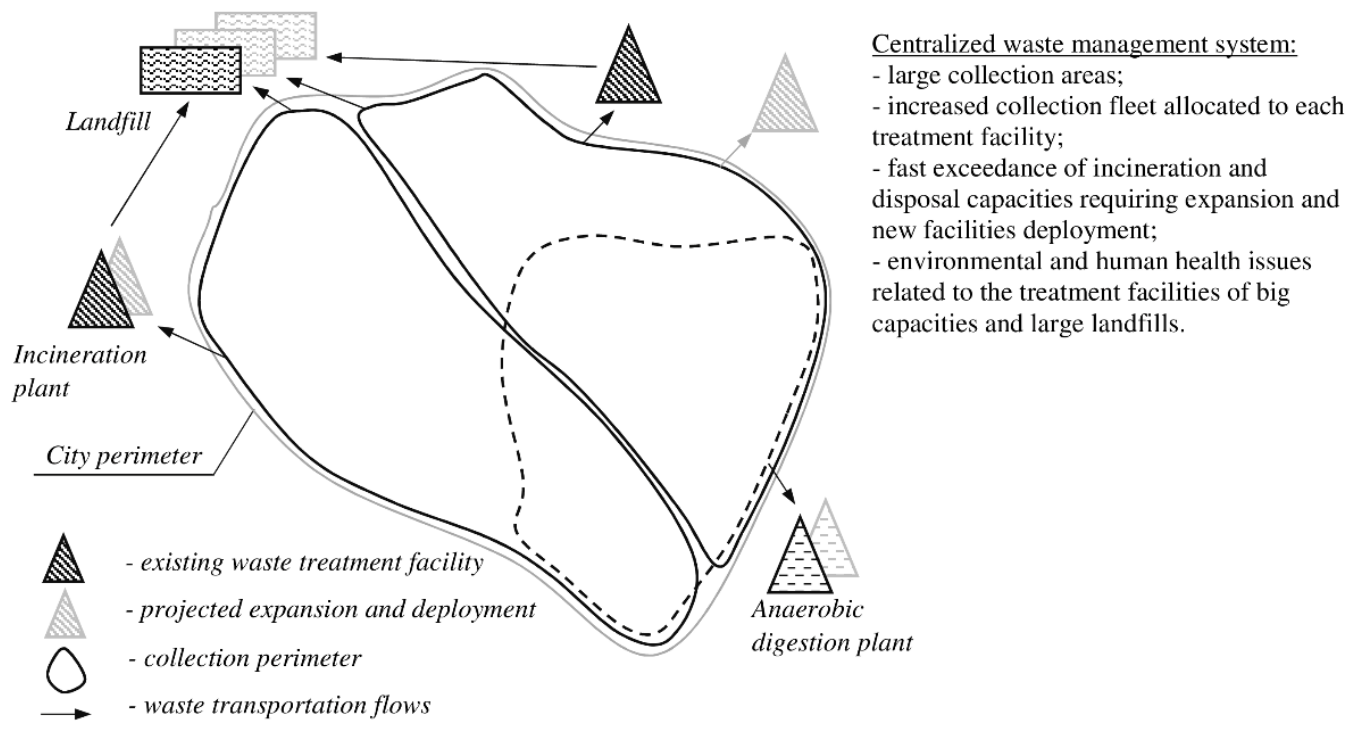

a) 


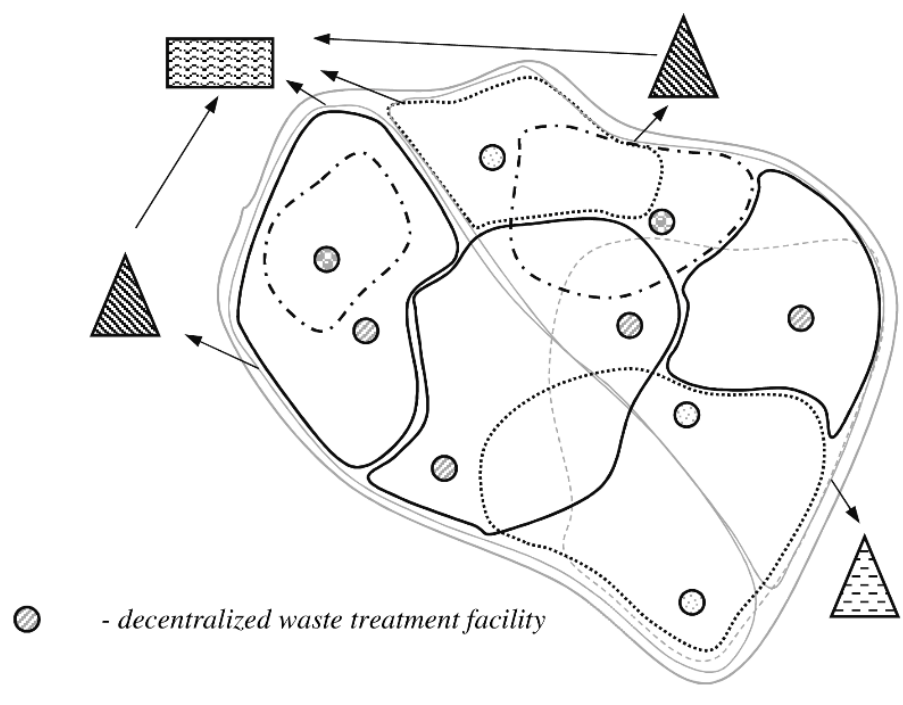

b)
Combined (centralized-decentralized) waste management system:

- reduced collection areas for decentralized facilities;

- reduced capacity of the new decentralized waste treatment facilities;

- location closer to waste generation sources and recovered energy/material users; - waste recycling adapted for each waste category promoting economy development and reducing environmental impact; - diversification of waste recycling technologies ensuring better global adaptability;

- reduced pressure on the existing centralized waste treatment infrastructure; - human health mitigation with the selection of suitable waste recovery technique according to individual technologies characteristics and local requirements.

Figure 1. Conceptual illustration of a MSW management system relying on a) centralized and b) combined centralized-decentralized WtEMS configurations.

\section{Expanded literature review}

This section summarizes the main research contributions presented in the introduction by enumerating the major bottlenecks and challenges for each. The analysis relies on the findings of the previously conducted extensive review of existing DSM, such as [19]. It also integrates recent bibliographical references in the area of MSW modelling and prediction, management system optimization, and solution assessment.

The major challenges related to MSW modeling concern the prediction of MSW output based on either the statistics of MSW generation or construction of complex prediction models relying on an available (although extended) number of input parameters (Table 1). The first group of these type of models, such as the one proposed in [23], struggles to capture changes in future MSW trends since their estimations are based on MSW historical data. They also do not account for the impact of other explanatory variables, such as taxes. The second group of prediction techniques involves big data analytics and implementation of extended surveys to perform spatially-distributed predictions [24], or reliance on advanced prediction models that integrate a large number of explanatory variables [25]. However, the relationship between MSW generation and explanatory variables is not usually explicitly identified. In view of this, additional data collection [24]-[26] and model training [23] may be required to perform MSW estimations for predictions over different time horizons. In addition, only a limited number of studies, such as [24], have attempted to provide global estimations of MSW outputs or other subcategories, or to model MSW distribution for urban territories. 
Table 1. Detailed review of the recent MSW prediction approaches.

\begin{tabular}{|c|c|c|c|c|c|}
\hline $\begin{array}{l}\text { Bibliographica } \\
1 \text { reference }\end{array}$ & Waste category & Tested approaches & $\begin{array}{l}\text { Modelled } \\
\text { period and } \\
\text { granularit } \\
\text { y }\end{array}$ & Explanatory variables ${ }^{(1)}$ & Case study \\
\hline$[24]$ & MSW & $\begin{array}{l}\text { Spatial auto regression } \\
(\mathrm{SAR}) \quad \text { and } \\
\text { geographically } \\
\text { weighted regression } \\
(\mathrm{GWR}) \text { models }\end{array}$ & $\begin{array}{l}\text { Total } \\
\text { generation } \\
\text { for } 1 \text {-year } \\
\text { period } \\
(2000)\end{array}$ & $\begin{array}{l}\text { Population density, higher education } \\
\text { graduation ratio, infant mortality rate, number } \\
\text { of facilities in small organized industrial } \\
\text { districts, agricultural production value, } \\
\text { asphalt-paved road ratio in rural areas, } \\
\text { unemployment rate, annual average } \\
\text { temperature, and annual rainfall }\end{array}$ & $\begin{array}{l}\text { Turkey } \\
\text { divided } \\
\text { into } 81 \\
\text { provinces }\end{array}$ \\
\hline [25] & $\begin{array}{l}\text { - Kitchen waste } \\
\text { - Recyclable } \\
\text { materials } \\
\text { - Other wastes }\end{array}$ & $\begin{array}{l}\text { Statistical analysis, a } \\
\text { sampling survey and } \\
\text { the Analytic } \\
\text { Hierarchy Process }\end{array}$ & $\begin{array}{l}5 \text { years } \\
\left(2004^{-}-\right. \\
2008), \\
\text { yearly } \\
\text { time step }\end{array}$ & $\begin{array}{l}\text { Activities: maintenance, subsistence and } \\
\text { leisure } \\
\text { Social parameters: floating population, non- } \\
\text { civil servants, retired people, civil servants, } \\
\text { college students (including both } \\
\text { undergraduates and graduates), primary and } \\
\text { secondary students, and preschoolers }\end{array}$ & $\begin{array}{l}\text { Beijing, } \\
\text { China }\end{array}$ \\
\hline$[26]$ & $\begin{array}{l}\text { Commercial } \\
\text { and household } \\
\text { waste }\end{array}$ & $\begin{array}{l}\text { Explorative data } \\
\text { analysis and } \\
\text { a multiple regression } \\
\text { analysis }\end{array}$ & $\begin{array}{l}\text { Total } \\
\text { generation } \\
\text { for 1-year } \\
\text { period } \\
(2001)\end{array}$ & $\begin{array}{l}23 \text { main variables divided into groups: Private } \\
\text { households and demographic variables, } \\
\text { economic variables, integrated waste } \\
\text { treatment facilities (local solid fuel heating } \\
\text { and composting), general indicators, } \\
\text { describing regional structure }\end{array}$ & $\begin{array}{l}\text { Styria } \\
\text { region, } \\
\text { Austria }\end{array}$ \\
\hline$[23]$ & MSW & $\begin{array}{l}\text { Support vector } \\
\text { machine, adaptive } \\
\text { neuro-fuzzy inference } \\
\text { system, artificial } \\
\text { neural network and k- } \\
\text { nearest neighbors }\end{array}$ & $\begin{array}{l}5 \quad \text { years } \\
\left(2015^{-}-\right. \\
2020), \\
\text { monthly } \\
\text { time step }\end{array}$ & Amount of waste generation & $\begin{array}{l}\text { Logan } \\
\text { city, } \\
\text { Australia }\end{array}$ \\
\hline$[27]$ & MSW & $\begin{array}{l}\text { General regression } \\
\text { neural network and } \\
\text { Structural break } \\
\text { general regression } \\
\text { neural network } \\
\text { models }\end{array}$ & $\begin{array}{l}2 \text { years } \\
(2011 \quad- \\
2012), \\
\text { yearly } \\
\text { time step }\end{array}$ & $\begin{array}{l}\text { GDP, urban population, average household } \\
\text { size, tourism expenditure, unemployed rates, } \\
\text { household expenditure, domestic material } \\
\text { consumption, population density, industry } \\
\text { value added, population from } 20 \text { to } 65 \text {, alcohol } \\
\text { consumption and } \mathrm{CO}_{2} \text { emission }\end{array}$ & $\begin{array}{l}44 \\
\text { countries } \\
\text { (OECD } \\
\text { and non- } \\
\text { OECD } \\
\text { countries) }\end{array}$ \\
\hline$[28]$ & $\begin{array}{l}\text { MSW divided } \\
\text { into recycled, } \\
\text { industrial and } \\
\text { domestic waste }\end{array}$ & $\begin{array}{l}\text { System dynamics } \\
\text { prediction model }\end{array}$ & $\begin{array}{l}40 \text { years } \\
\left(2005^{-}-\right. \\
2045), \\
\text { five-year } \\
\text { time step }\end{array}$ & $\begin{array}{l}\text { total population, birth rate, industrial gdp, } \\
\text { industrial growth rate }\end{array}$ & Singapore \\
\hline
\end{tabular}

(1) The input variables used in the prediction approaches to estimate waste generation.

The major recent developments involved solving the problems of facility allocation, technology selection, and capacity expansion (Table 2). By extension, these studies can be naturally connected to MSW modelling since optimization models require inputs related to the amounts and location of generated wastes and to assessments of the sustainability of MSW management strategies. However, current optimization approaches usually rely on statistical data related to a specific case study. 
Table 2. Research topics addressed in recent bibliographical references.

\begin{tabular}{|c|c|c|c|c|c|c|}
\hline \multirow[t]{4}{*}{ Reference } & \multicolumn{6}{|c|}{ Research topics as core pillars of DSM } \\
\hline & \multirow{2}{*}{$\begin{array}{l}\text { Waste } \\
\text { modeling and } \\
\text { prediction }\end{array}$} & \multicolumn{4}{|c|}{ Optimization } & \multirow{2}{*}{$\begin{array}{l}\text { Solution } \\
\text { assessment }\end{array}$} \\
\hline & & $\begin{array}{l}\text { Vehicle } \\
\text { routing }\end{array}$ & $\begin{array}{l}\text { Facilities } \\
\text { location }\end{array}$ & $\begin{array}{l}\text { Technologies and } \\
\text { connection to the } \\
\text { end user }\end{array}$ & Size/capacity & \\
\hline & $\begin{array}{l}\text { Realistic } \\
\text { representation } \\
\text { of the } \\
\text { amounts and } \\
\text { types of } \\
\text { generated } \\
\text { waste in a } \\
\text { given } \\
\text { territory }\end{array}$ & $\begin{array}{l}\text { The amount } \\
\text { of waste to be } \\
\text { transported; } \\
\text { vehicle } \\
\text { routing and } \\
\text { fleet }\end{array}$ & $\begin{array}{l}\text { Selection of } \\
\text { optimal } \\
\text { location for a } \\
\text { treatment } \\
\text { facility for a } \\
\text { given number } \\
\text { of candidate } \\
\text { locations }\end{array}$ & $\begin{array}{l}\text { Selection of } \\
\text { optimal treatment } \\
\text { technologies and } \\
\text { energy /material } \\
\text { output }\end{array}$ & $\begin{array}{l}\text { Expansion of } \\
\text { facility for } \\
\text { the long-time } \\
\text { planning } \\
\text { horizon, } \\
\text { assignment to } \\
\text { different } \\
\text { treatment } \\
\text { technologies }\end{array}$ & $\begin{array}{l}\text { Complex } \\
\text { assessment } \\
\text { framework } \\
\text { taking into } \\
\text { account } \\
\text { economic, } \\
\text { environmental } \\
\text { and social } \\
\text { considerations }\end{array}$ \\
\hline$[32]$ & & & $\mathrm{X}$ & $\mathrm{X}$ & $\mathrm{X}$ & $\mathrm{X}$ \\
\hline$[10]$ & & $\mathrm{X}$ & $\mathrm{X}$ & & & \\
\hline$[33]$ & & $\mathrm{X}$ & $\mathrm{X}^{(1)}$ & & & \\
\hline [34] & & & $\mathrm{X}$ & $\mathrm{X}$ & $\mathrm{X}$ & $\mathrm{X}^{(2)}$ \\
\hline$[35]$ & $\mathrm{X}$ & & & $\mathrm{X}$ & $\mathrm{X}$ & \\
\hline [29] & & & & $\mathrm{X}$ & & $\mathrm{X}$ \\
\hline$[30]$ & & & & $\mathrm{X}$ & & $\mathrm{X}$ \\
\hline$[31]$ & & & & $\mathrm{X}$ & & $\mathrm{X}$ \\
\hline
\end{tabular}

(1) The facility location problem is approximated by a waste assignment problem where CAPEX represents plant opening cost.

(2) Environmental impact is accounted for in the objective function through $\mathrm{CO}_{2}$ emissions monetization.

Table 3 summarizes the key details of the reviewed optimization approaches for MSW management system deployment.

In most of the papers reviewed, except [32], the optimization models did not include a selection of waste treatment technology for each candidate site. Each candidate site was predefined for the deployment of a specific waste treatment technology, e.g., incineration or biomass treatment. Although this can be explained by specific urban constraints and requirements, it restricted exploration of the types of technologies considered for deployment at each site. In addition, many studies [32], [34], [35], did not distinguish between centralized and decentralized waste treatment facilities. This oversight is of note because the maximum treatment capacity for decentralized facilities can be considerably different (e.g., up to $10^{6}$ times smaller) than the maximum capacity of centralized facilities. Therefore, decentralized deployment implies different company sizes and business models, which generate different investments and operation costs per ton of waste treated in comparison with the more sizeable centralized facilities. 
Table 3. Detailed review of selected deployment approaches.

\begin{tabular}{|c|c|c|c|c|}
\hline $\begin{array}{l}\text { Bibliographical } \\
\text { reference }\end{array}$ & $\begin{array}{l}\text { Aim of the optimization } \\
\text { approach and case study }\end{array}$ & $\begin{array}{l}\text { System specific focus - waste categories and } \\
\text { waste treatment technologies }\end{array}$ & $\begin{array}{lr}\text { Objective } & \text { function and } \\
\text { additional } & \text { assessment } \\
\text { indicators } & \\
\end{array}$ & $\begin{array}{l}\text { Deployment } \\
\text { horizon }\end{array}$ \\
\hline$[32]$ & $\begin{array}{l}\text { NPV optimization of } \\
\text { recycling and disposal } \\
\text { network in Tehran (Iran) } \\
\text { Waste generator clustering } \\
\text { around collection points or } \\
22 \text { municipalities centers. }\end{array}$ & $\begin{array}{l}\text { Waste categories: plastic, glass, paper, metal, } \\
\text { organic, others. Transformation into recyclable } \\
\text { material (plastic, paper and metal), electricity, } \\
\text { compost fertilizer. } \\
\text { Technologies: material recovery facilities, } \\
\text { anaerobic digester, composting facilities, } \\
\text { landfill with gas recovery system, advanced } \\
\text { thermal treatment (pyrolysis and gasification). } \\
\text { Off-site centralized facilities of important } \\
\text { capacity (about } 250-500 \text { tons/day) }\end{array}$ & $\begin{array}{l}\text { Revenues (output generation } \\
+ \text { gate fees for waste } \\
\text { processing) } \\
\text { CAPEX } \\
\text { OPEX } \\
\text { Environmental cost }\end{array}$ & $\begin{array}{l}\text { Medium }-5- \\
\text { year } \\
\text { planning } \\
\text { horizon }\end{array}$ \\
\hline$[10]$ & $\begin{array}{l}\text { Selection location for } \\
\text { transfer station for waste } \\
\text { collection } \\
\text { Hypothetical urban center } \\
\text { of } 192 \mathrm{~km}^{2} \text { and } 1.8 \text { million } \\
\text { of habitant in } 2035\end{array}$ & $\begin{array}{l}\text { Waste categories: compostable, recyclable and } \\
\text { landfill. } \\
\text { Accounts for different collection schedules, } \\
\text { transportation capacities of public and private } \\
\text { companies from residential, commercial and } \\
\text { institutional sources. }\end{array}$ & $\begin{array}{l}\text { CAPEX of transfer station } \\
\text { deployment } \\
\text { OPEX for transportation and } \\
\text { operation of existing and } \\
\text { deployed facilities }\end{array}$ & $\begin{array}{l}\text { Lon-term - } \\
\text { 20-year } \\
\text { planning } \\
\text { horizon }\end{array}$ \\
\hline$[33]$ & $\begin{array}{l}\text { Optimization of waste } \\
\text { transfer, collection truck } \\
\text { management strategies, } \\
\text { optimal locations for new } \\
\text { waste treatment facilities } \\
\text { Hong Kong (waste transfer } \\
\text { to China is a possible } \\
\text { feasible solution) }\end{array}$ & Technologies: incineration and landfills & $\begin{array}{l}\text { CAPEX (incinerator and } \\
\text { warehouse) } \\
\text { OPEX (operational cost in the } \\
\text { incinerator and landfill, } \\
\text { transportation cost from } \\
\text { each two points, cost of } \\
\text { moving replacement truck to } \\
\text { waste collection point and } \\
\text { incinerator, truck cost) } \\
\text { Revenues (from incinerator) }\end{array}$ & $\begin{array}{l}\text { Short-term- } \\
\text { 1-year } \\
\text { planning } \\
\text { horizon }\end{array}$ \\
\hline [34] & $\begin{array}{l}\text { NPV of WtE facilities and } \\
\text { associated electricity grid } \\
\text { and heating/cooling } \\
\text { infrastructures deployment } \\
\text { Thessaly district, } \\
\text { Greece }\end{array}$ & $\begin{array}{l}\text { Biomass-type waste from MSW and } \\
\text { agricultural sources related to wheat straw, } \\
\text { maize, cotton stalks and prunings from olive } \\
\text { and almond trees. }\end{array}$ & $\begin{array}{l}\text { CAPEX } \\
\text { OPEX (related to the power } \\
\text { plant, the supply chain of } \\
\text { MSW and biomass, the district } \\
\text { heating and cooling (district } \\
\text { energy) network with the } \\
\text { connection to the customers, } \\
\text { as well as the electricity } \\
\text { transmission line and } \\
\text { connection to the grid) } \\
\text { Revenues }\end{array}$ & $\begin{array}{l}\text { Long-term - } \\
\text { 20-year } \\
\text { planning } \\
\text { horizon }\end{array}$ \\
\hline$[35]$ & $\begin{array}{l}\text { Waste generation } \\
\text { prediction and expansion of } \\
\text { the existing composting and } \\
\text { incineration facilities in } \\
\text { Beijing, China }\end{array}$ & $\begin{array}{l}\text { Technologies: landfill, composting and } \\
\text { incineration. }\end{array}$ & $\begin{array}{l}\text { CAPEX } \\
\text { OPEX } \\
\text { Revenues }\end{array}$ & $\begin{array}{l}\text { Medium -5- } \\
\text { year } \\
\text { planning } \\
\text { horizon }\end{array}$ \\
\hline [29] & $\begin{array}{l}\text { Waste assignment to } \\
\text { different waste treatment } \\
\text { facilities in Genova, Italy }\end{array}$ & $\begin{array}{l}\text { Waste categories: paper, plastic, glass, wood, } \\
\text { organic, metals, inert matter, scraps, textiles } \\
\text { Technologies: landfill, incineration plant, } \\
\text { plant for organic materials treatment and } \\
\text { refuse derived fuel plant }\end{array}$ & $\begin{array}{l}\text { OPEX } \\
\text { Revenues } \\
\text { Unrecycled waste } \\
\text { Sanitary landfill disposal } \\
\text { Environmental impact } \\
\text { (incinerator emissions) } \\
\end{array}$ & $\begin{array}{l}\text { Short-term- } \\
\text { 1-year } \\
\text { planning } \\
\text { horizon }\end{array}$ \\
\hline$[30]$ & $\begin{array}{l}\text { Waste management for the } \\
\text { abstract case study of three } \\
\text { cities in China }\end{array}$ & $\begin{array}{l}\text { Waste categories: glass and other types of } \\
\text { waste } \\
\text { Technologies: glass recycling plant, } \\
\text { incineration and sanitary landfill }\end{array}$ & $\begin{array}{l}\text { OPEX (collection, } \\
\text { transportation, recycling, } \\
\text { treatment and disposal costs) } \\
\text { Risks associated to waste } \\
\text { management procedures and } \\
\text { technology used }\end{array}$ & $\begin{array}{l}\text { Medium -5- } \\
\text { year } \\
\text { planning } \\
\text { horizon }\end{array}$ \\
\hline$[31]$ & $\begin{array}{l}\text { Waste management for the } \\
\text { case study of five cities in } \\
\text { Mexico, each one divided } \\
\text { into } 10 \text { subzones. }\end{array}$ & $\begin{array}{l}11 \text { waste categories including MSW, brown } \\
\text { glass, paper, aluminum and non-recyclable } \\
\text { waste. } \\
\text { Technologies: material recycling, thermal and } \\
\text { chemical recycling, pyrolysis, incineration, } \\
\text { pyrolysis and gasification, plasma arc } \\
\text { gasification, conventional gasification }\end{array}$ & $\begin{array}{l}\text { Net profit (Revenues, CAPEX } \\
\text { and OPEX) } \\
\text { Amount of processed waste } \\
\text { Total number of fatalities }\end{array}$ & $\begin{array}{l}\text { Short-term - } \\
\text { 1-year } \\
\text { planning } \\
\text { horizon }\end{array}$ \\
\hline
\end{tabular}


Another bottleneck is related to the way environmental and social impacts of MSW management systems are integrated as part of the DSM. To avoid compromising computational tractability, multi-objective optimization may require aggregating several objectives into one function, either by converting environmental impacts into an economic unit of global optimization objective [32] or by using a weighting approach to aggregate social risk [30]. Despite allowing easy aggregation, this method may underestimate the weights or prices of different objectives and "hide" their effects on optimization results. Another way to illustrate the optimization trade-off is to perform a classical multi-objective optimization. This may imply greater complexity for the optimization model and can drastically increase the computational burden in comparison with single-objective optimization. This requires a range of assumptions or simplifications to deal with the computational complexity that arises, e.g., by adopting a reference point [29] or obtaining Pareto fronts through optimization of individual objectives [31]. In this view, the attempt to incorporate LCA, or social oriented criteria, into the optimization model poses additional challenges to it, such as the introduction of a greater complexity into the problem, tractability, and the difficulty of aggregating different objectives into one term. To date, no multi-criteria assessment framework based on economic, environmental, and social indicators exists to assess the sustainability of an MSW management system.

\section{Integrated Decision Support Methodology (DSM)}

The paper proposes an integrated DSM by addressing the aforementioned challenges. In addition, a promising solution to overcome the limitations of individual approaches lies in the combination of modeling, optimization, and assessment frameworks for the development of the extended models. Figure 2(a) depicts the DSM flowchart composed of three main modules: (1) the waste modelling and prediction, (2) optimization of WtEMS, and (3) a multidimensional assessment. In Step 1, the MSW sources are categorized and their distribution across the urban territory is modelled. By relying on the projections for explanatory variables, e.g., demographic and economic conditions, this module provides MSW source predictions and helps quantify uncertainties in MSW generation for all planning horizon durations (Figure 2(b)). These MSW output scenarios, as well as data related to the abstract models of waste treatment technologies, are used as input data in Step 2 focusing on WtEMS optimization. The optimization module encompasses all related technical and cost parameters and, guided by the optimization objective, aims at finding the optimal configuration for the WtEMS. After the optimization module yields an optimal deployment plan, Step 3 evaluates it using a multicriterion assessment framework. The assessment module uses the base line MSW treatment strategy typically represented by the current MSW treatment with incineration. The waste treatment strategy assessment can be done under projections of future operational conditions, e.g., resource costs or specific urban planning conditions, and can lead to the update of the specific optimization model constraints. In this view, projections of economic conditions and urban planning strategies may lead to adjustments of the optimization constraints related to maximum available local space for waste technology deployment in order to improve the final sustainability key performance indicator (KPI) of the global WtEMS solution. Eventually, after 
multi-criteria assessment of different WtEMS and comparison with benchmark scenario is done, optimal WtEMS designs with the associated deployment schedule can be selected.

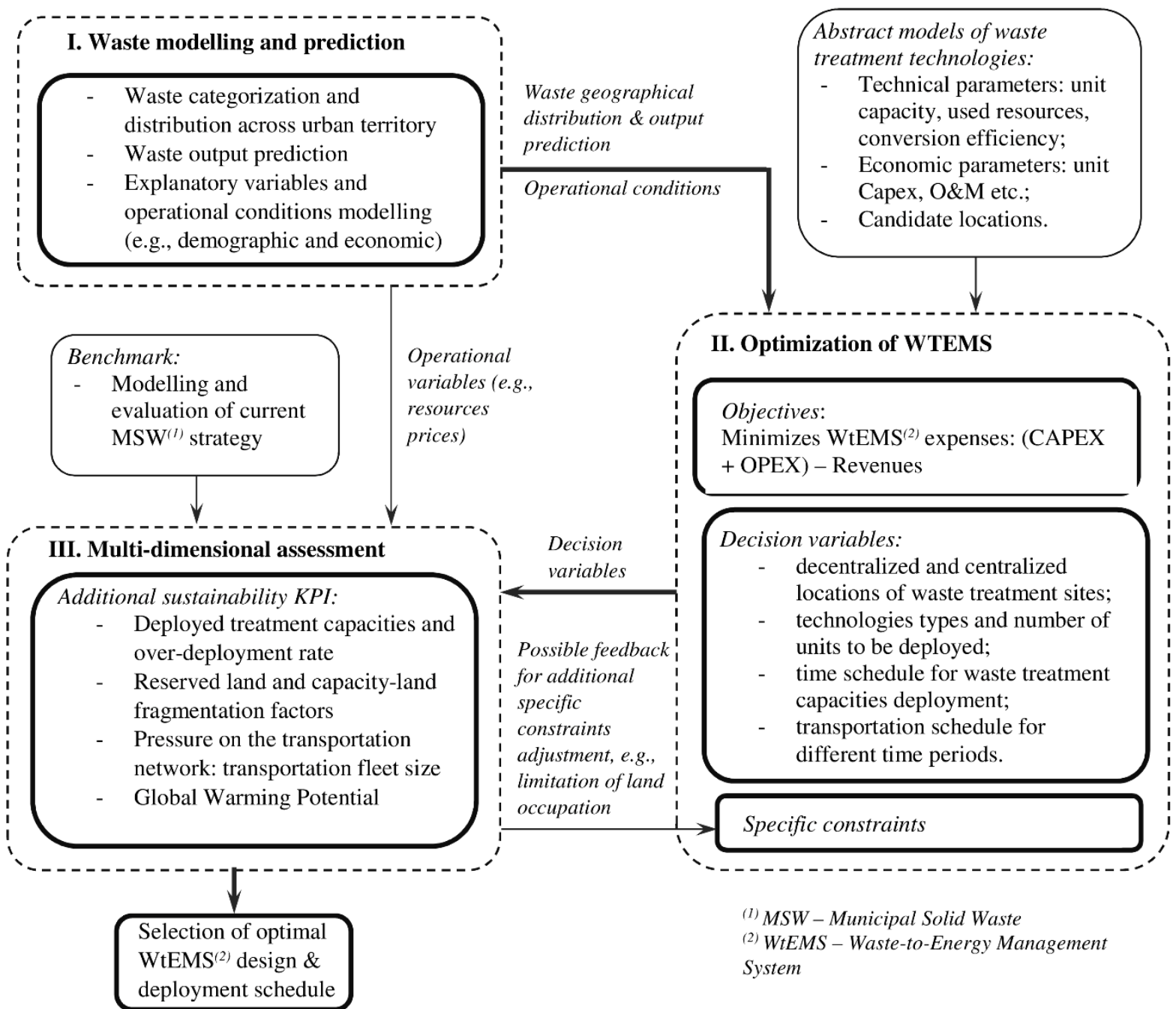

a)

Time intervals
( year)
Prediction \&
planning

Optimization

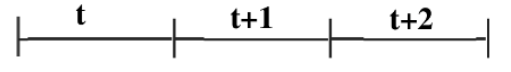

Current

(nominal)

operational
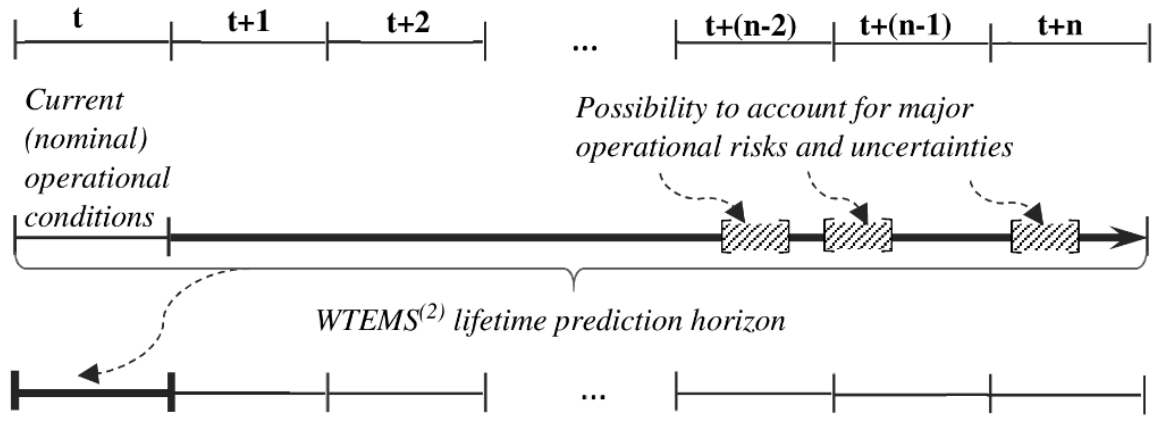

Possibility to account for major

operational risks and uncertainties

Decision about optimal WTEMS ${ }^{(2)}$

configuration and it

deployment schedule

planning 
Figure 2. Integrated DSM for WtEMS design: a) methodology flowchart and b) WtEMS design procedure.

\subsection{MSW distribution across urban territories}

Several attempts have been made to narrow waste quantification by categories. These attempts are mainly based on long-term campaigns of waste sampling covering large territories and interviews at various stages of the existing MSW management systems. The general tendency of MSW segregation by category is summarized in [3] that discussed similar waste proportions in different regions across the globe.

However, the waste management system is a spatial problem requiring not only knowledge of the global amounts of MSW generated in a territory, but also an understanding of the distribution of these sources across this territory, which is also referred as the "geography of waste". Indeed, WGS quantification and distribution impact not only the choice of waste treatment technologies, but also waste collection and transportation, e.g., fixed routines for regularly produced waste of large amounts, infrequent schedules for seasonal waste, and upon request collection for irregular and bulky waste types [36]. The waste management system of each territory is defined by its administrative subdivision responsible for performing, organizing (e.g., hiring private companies) and supervising waste management profiles. For example, waste management profiles have been found to differ by metropolitan areas regrouped into regions in Turkey [37], by municipalities in the Metropolitan Region of São Paulo (Brazil) [38], and by urban districts or communes in the municipality of Bamako (Mali) [39]. In this view, the waste management follows the municipal ordinances for collecting waste management taxes and prescribing collection routes, frequency, bin systems, etc. [36].

However, WGS are usually non-uniformly distributed across urban territories depending on residential, commercial, office, industrial and mixed activities subzones, illustrated in Figure 3(a), with different waste distribution proportions for each waste category. The MSW is broken down into categories and analyzed to determine its sources (i.e., activities subzones) and associated factors affecting its waste generation and distribution (Figure 3(b)). Subsequently, the activities subzones are analyzed and linked to specific datasets characterizing those subzones. Apart from industry data and population census, historical data on waste generation and distributions will be required for modeling and validation purposes. Another reason to model the waste distribution by administrative subzones lies in the typical availability of datasets by these administrative subdivisions. 


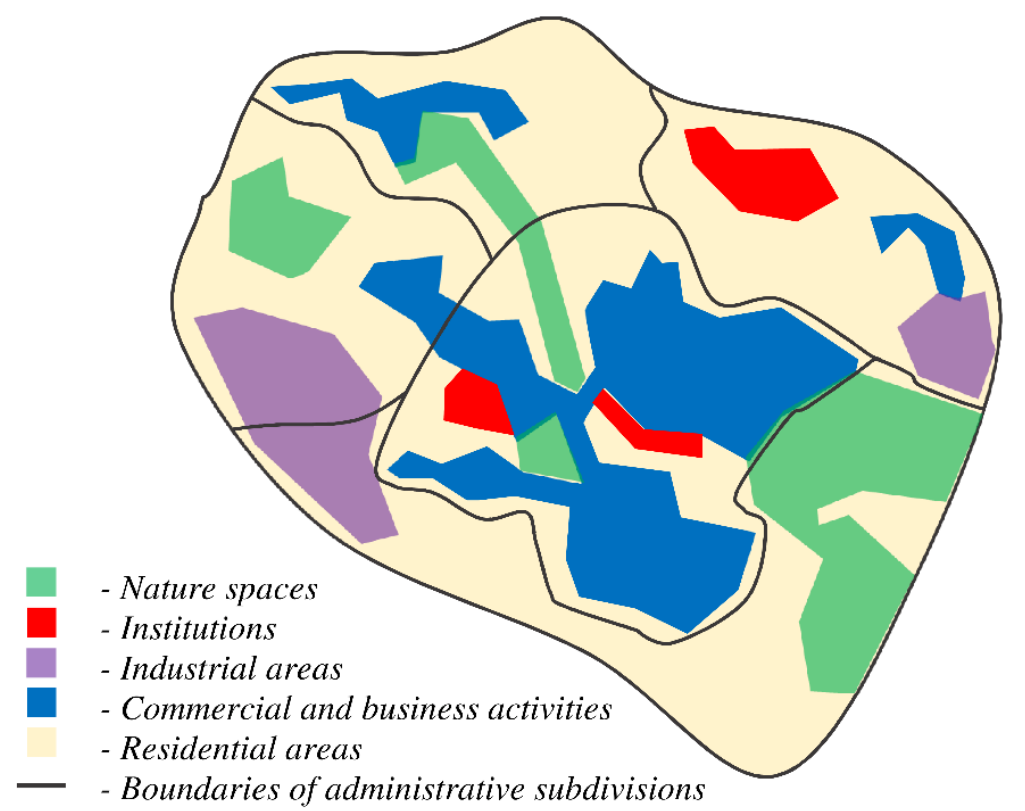

a)

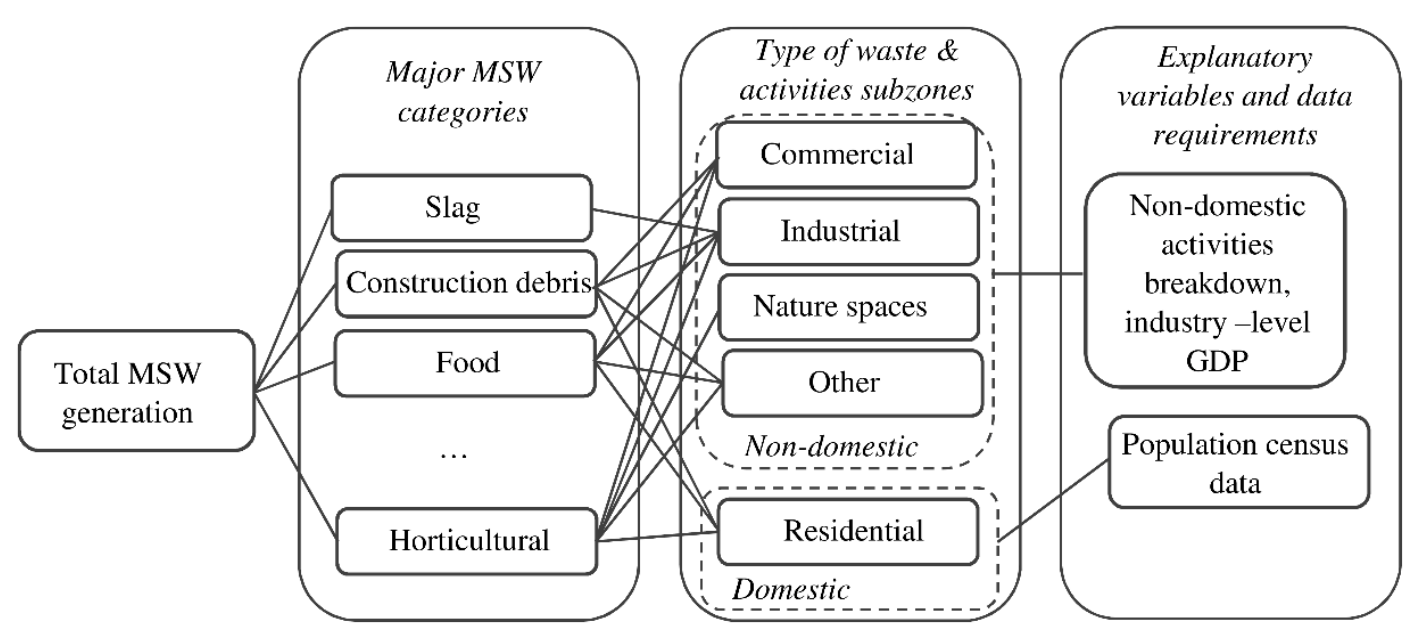

b)

Figure 3. MSW analysis: a) abstract illustration of urban territory subdivision on the activities and administrative subzones and b) steps for MSW profiling.

The first step to determine the MSW distribution starts with profiling the subzones and waste types for a better understanding of associated explanatory variables. This information can then be used for a weight calculation for each waste type in each subzone. In this view, it is ideal to identify the breakdown of activities in each subzone for accurate modeling of waste distributions, e.g., on manufacturing, retail and construction, and their intensity. However, since such specific information is usually unavailable, more generalized methods and assumptions can be used to obtain waste distributions. 


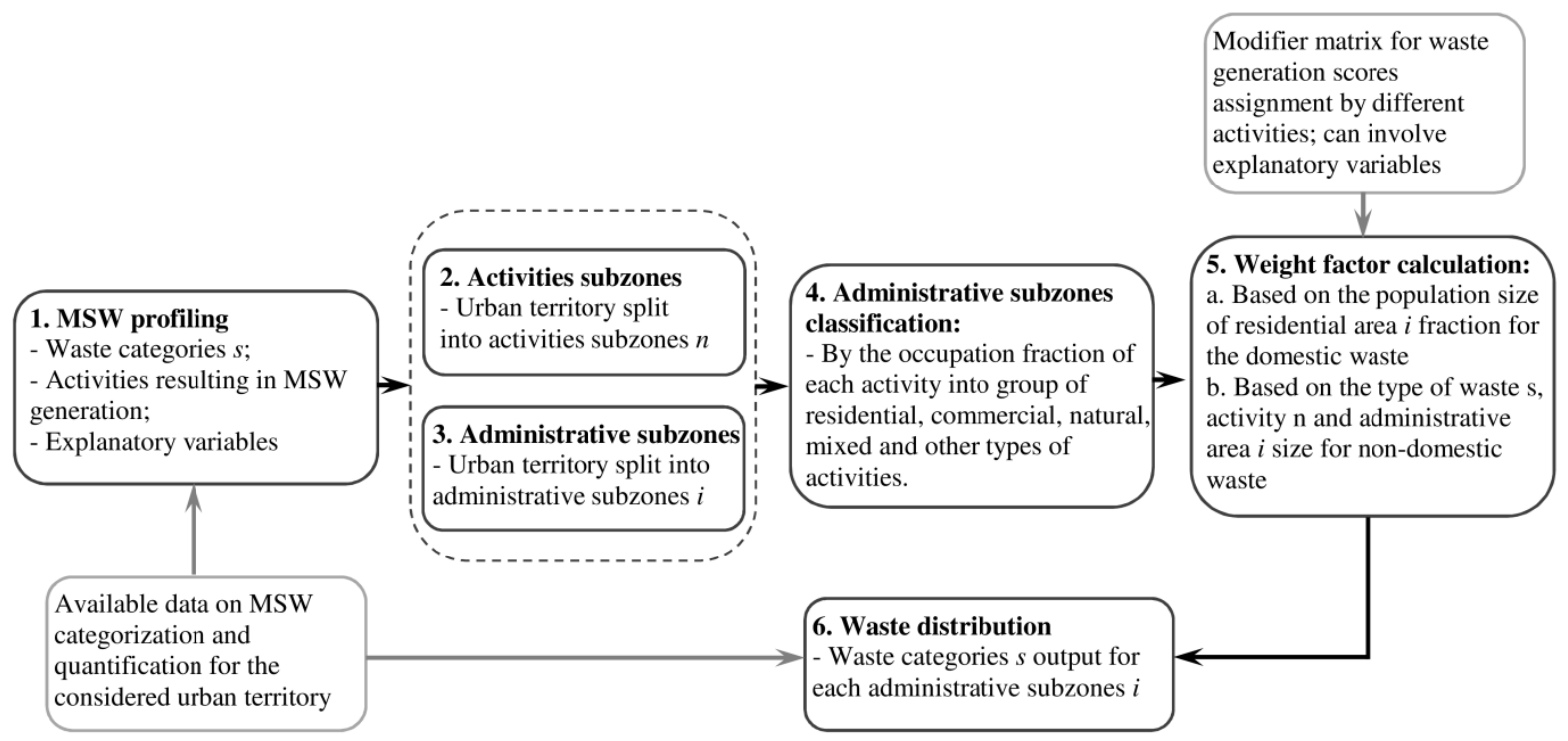

Figure 4. Framework for modeling of MSW distribution across urban territories.

The procedure for waste distribution modeling across territories is as follows:

1. MSW profiling. Following the example of MSW profiling in Figure 3(c), MSW must be analyzed and split into categories defined by scenario, $s$. These categories can be related to the global MSW categories identified and quantified for the whole urban area. The possible activities, responsible for the generation of each of the waste categories in urban territory, along with explanatory variables, must be identified.

2. Activities subzones. The urban territory of interest must be split into the activities subzones, $n$. This split can be supported by the data issued from urban development strategies (Figure 3(a)).

3. Administrative subzones. The division of the same urban territory into administrative subzones, $i$, according to urban governance structure, e.g., by districts (Figure 3(b)), must be performed.

4. Administrative subzones classification. Each administrative subzone must be classified by the occupation fraction of each urban activity. The framework proposes the classification into residential, industrial, commercial, natural, mixed, and other types of activities groups.

5. Weight factors calculation. The subzone layer calculates the weightage of each relevant land occupation by different urban activities. For example, under domestic waste, the relevant subzones are residential subzones. In this view, the residential population in each subzone will be weighed against the total residential subzone population to obtain a weight or fraction of the domestic waste generated in each subzone. The sum of all subzones weights is equal to1.

a. Domestic Waste 
Domestic waste is generated from only residential areas and the population is chosen as the weightage factor. The domestic subzone weightage (DSW) for domestic waste is calculated based on its residential population:

$$
\text { DSW }_{i}=\frac{\text { Population }_{i}}{\sum_{i} \text { Population }_{i}}, \text { for } i \in \mathrm{C}
$$

where $C$ is the set of subzones $i$ with residential classification.

Subzones that do not have residential occupations have been assigned with a zero weightage for domestic waste.

b. Non-Domestic Waste

For non-domestic waste, the intensity of activities has been assumed to be proportional to the territory occupied by this activity, i.e., more land space leads to greater intensity of the activity or business transactions. In this view, the land area is used as the weightage factor. However, commercial spaces are likely to be denser in terms of their activities and, thus, in specific waste generation per land area than the mixed land categories. To take this into account, a modifier matrix is introduced to calculate the effective area matrix (EAM) as a weightage factor appropriately:

$$
E A M_{i, s}=M_{s, n} \cdot A_{i, n}
$$

where $s$ is the scenario defining MWS categories under consideration, $n$ is the number of activities/purpose selected for subzone $i$ classification. The land area matrix, $A_{i, n}$, is calculated by multiplying an occupation fraction by the land area of the corresponding subzone. In case additional data is available for the explanatory variables influencing MSW generation, the waste output can be adjusted through the Modifier matrix, $M_{s, n}$. This possibility is discussed further in Section 24.

The non-domestic subzone weightage (NDSW) for scenario, $s$, in subzone, $i$, is calculated as:

$$
N D S W_{s, j}=\frac{E A M_{i, s}}{\sum_{i} E A M_{i, s}}
$$

6. Waste distribution. By using global records on the amounts of MSW categories and weight factors for domestic and non-domestic MSW, the actual waste distribution across urban territories is calculated. 


\subsection{Optimization of waste management}

\subsubsection{Overview and assumptions for the optimization model}

Figure 5 presents the conceptual superstructure for WtEMS deployment including WGS, energy, and material flows exchanged in the urban territory and surrogate model of waste treatment technology.

The assumptions underlying the optimization model are as follows:

- The term "on-site machine" refers to the decentralized facilities (DF) of smaller capacity located in the proximity of each waste source. Conversely, the term "off-site machine" refers to the centralized facility $(\mathrm{CF})$ of larger capacity treating waste flows transported from different WGS.

- Each WGS, as well as the candidate site for deployment, is abstracted as a geographical (waste generation and treatment) node. The distance between a WGS and a candidate site (DF or CF) is calculated based on the longitude and latitude coordinates by applying the triangle location algorithm [40].

- All candidate locations can host various waste treatment technologies targeted by the decision-maker. The on-site installed capacity has to be such that the on-site installed machine can process all waste generated locally without transportation of any outstanding waste to off-site facilities to limit transportation flows.

- The capacities of on-site and off-site Waste Treatment Facility (WTF) cannot be reduced upon deployment.

- The optimization model has been developed using global planning perspectives and does not account for economic relationships between WtEMS stakeholders. In this view, no disposal cost or tipping fees have been considered in the model.

- The optimization model for deployment of MSW treatment infrastructure has been formulated conceptually and independently from the MSW source type considered for infrastructure deployment. In this view, the theoretical framework can deal with various types of MSW, e.g., paper and cardboard, horticultural waste and plastic, and associated treatment technologies as model inputs. 


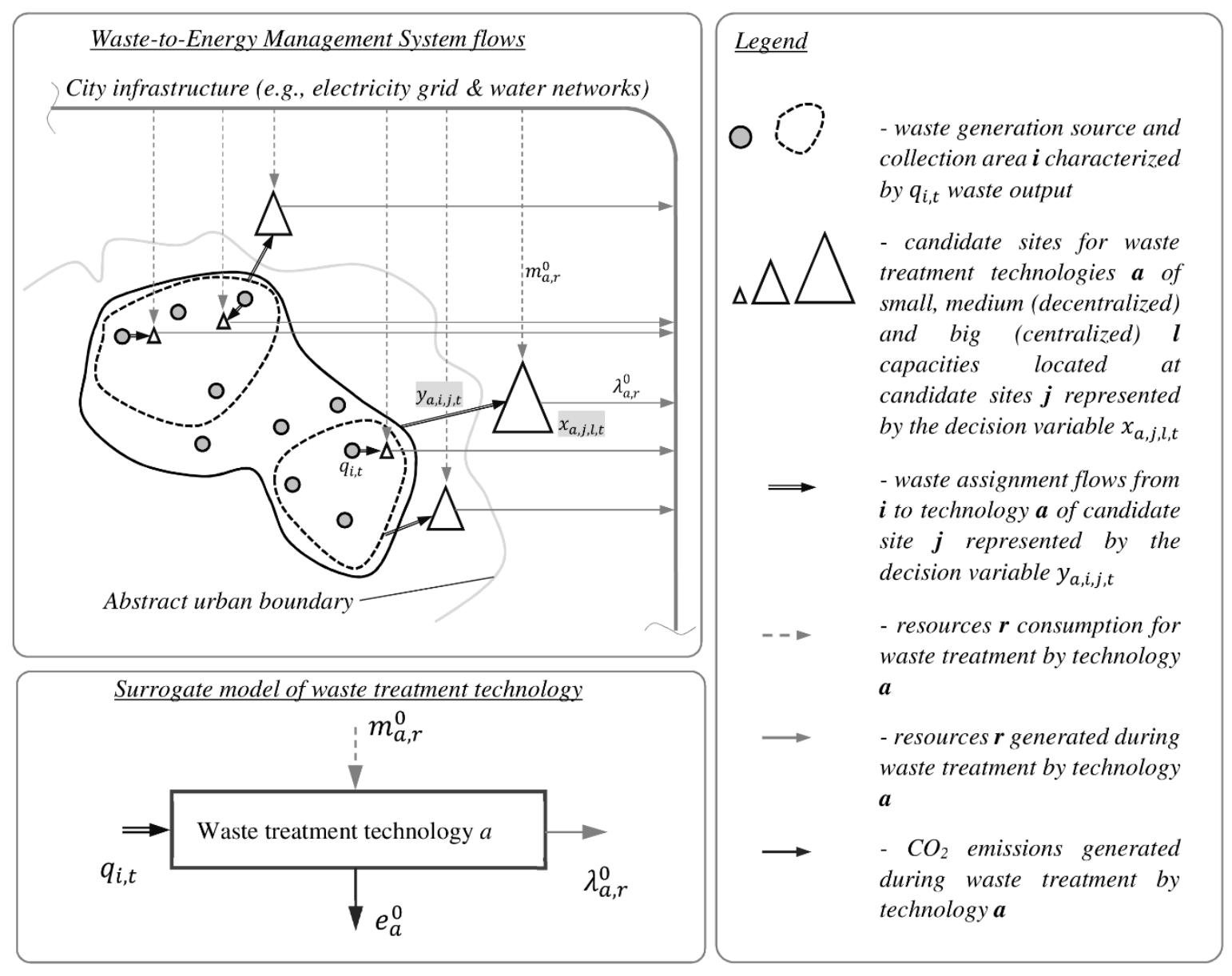

Figure 5. Conceptual superstructure of WtEMS.

\subsubsection{Optimization model formulation}

The optimization model has been formulated as a mixed integer linear programming (MILP). The objective is to minimize the "absolute" expenses over the long-term period, $T$, represented as the differences between the total costs (Eq. (6)) and the revenues, $P_{R V}$, obtained from the resources recovery (Eq. (5)):

$$
\begin{gathered}
\min _{x, y}\left(C_{T}-P_{R V}\right) \\
P_{R V}=\sum_{t=0}^{T} \frac{1}{(1+r)^{t}} \sum_{I} \sum_{A} \sum_{R} p_{r}^{0} \cdot \lambda_{a, r}^{0} \cdot q_{i, t}
\end{gathered}
$$

By taking into account the aforementioned installation cost, $C_{C A P E X}$, and operation cost, $C_{O P E X}$, the total WtEMS cost, $C_{T}$, over a period, $T$, is defined as the summation of all relevant costs discounted over lifecycle period, $T$, to obtain the net present value of future cash flows: 


$$
C_{T}=\sum_{t=0}^{T} \frac{1}{(1+r)^{t}}\left[C_{\text {CAPEX }_{t}}+C_{\text {OPEX }_{t}}\right]
$$

The optimization problem accounts for the installation cost of WTF for which capacity can be progressively deployed during a long-term planning horizon (from several years up to decades). For more convenience, the investment cost has been divided into two terms: (i) initial investment cost at time $t=0$ and (ii) deployment cost for the remaining future planning horizon for $t=1, \ldots, T$ :

$$
\begin{gathered}
C_{\text {CAPEX }}=\sum_{J} \sum_{L} \sum_{A} c_{a, l}^{0} \cdot x_{a, j, l, t}, t=0 \\
C_{C A P E X_{t}}=\sum_{J} \sum_{L} \sum_{A} c_{a, l}^{0} \cdot z_{a, l} \cdot\left(x_{a, j, l, t}-x_{a, j, l, t-1}\right), t=1, \ldots, T
\end{gathered}
$$

where

$$
z_{a, l}=l^{E o S_{a}}-(l-1)^{E o S_{a}}
$$

The EoS factor has been also integrated in Eqs. 9 - 11 to account for the reduction in variable costs. It is of note that the EoS factors for different costs can vary for different industries and types of plants. However, it has been concluded that many plants exhibit substantial savings due to their increased capacities [41]. For the purpose of this study, the same formulation of EoS based on the capacity expansion has been assumed for fixed and variables costs.

The operational cost, $C_{O P E X}$, encompasses transportation, $C_{T R S_{t}}$, land use, $C_{L D_{t}}$, operation and maintenance, $(\mathrm{O} \& \mathrm{M}) C_{O M}$, manpower, $C_{M P}$, cost of additional resources required for waste recovery (e.g., water and electricity inputs), $C_{R C_{t}}$, and pollution $\operatorname{cost} C_{P L_{t}}$ :

$$
C_{O P E X_{t}}=C_{T R S_{t}}+C_{O M_{t}}+C_{L D_{t}}+C_{M P_{t}}+C_{P L_{t}}+C_{R C_{t}}, t \in T .
$$

The transportation cost, $C_{T R S}$, is proportional to the transportation distances and the amount of waste allocated to each technology installed at candidate site, $j$ :

$$
C_{T R S_{t}}=365 \cdot c^{1} \sum_{I} \sum_{J} D_{i, j} y_{a, i, j, t}\left\lceil\frac{q_{i, t}}{k^{2}}\right\rceil, t \in T .
$$

Expenditures involving O\&M, land use, and manpower are calculated by using Eq. (12), Eq. (13), and Eq. (14), respectively. For simplicity, the EoS factor for these variable costs has been expressed as a function of installed capacity: 


$$
\begin{gathered}
C_{O M_{t}}=\sum_{A} z_{a, l} \cdot c_{a}^{2} \sum_{L} \sum_{J} x_{a, j, l, t}, t \in T \\
C_{L D_{t}}=\sum_{L} \sum_{J} \sum_{A} z_{a, l} \cdot c_{l, a, j}^{3} \cdot x_{a, j, l, t}, t \in T \\
C_{M P_{t}}=\sum_{L} \sum_{A} z_{a, l} \cdot c_{l, a}^{4} \sum_{J} x_{a, j, l, t}, t \in T
\end{gathered}
$$

The pollution cost $C_{P L_{t}}$ Eq. (15) consists of two parts: (i) the amount of waste transported from the WGS to WTF and (ii) the emissions generated by the waste treatment activities:

$$
\begin{aligned}
C_{P L_{t}}=c^{5}\left(365 \cdot e^{1} \sum_{I} \sum_{J} \sum_{A} D_{i, j} y_{a, i, j, t}\left\lceil\frac{q_{i, t}}{k^{2}}\right\rceil\right. \\
\left.+e_{a}^{0} \sum_{I} \sum_{J} \sum_{A} y_{a, i, j, t}\left(q_{i, t}-u_{t}^{+}\right)\right), t \in T
\end{aligned}
$$

It is of note that the pollution cost integrated in the $C_{O P E X}$ can account for the specific economic measures for the reduction in $\mathrm{CO}_{2}$ emissions adopted in different countries.

Finally, during waste recovery, WTF consumes energy and materials (e.g., electricity and water). The expense for the consumption of these resources is monetized with $C_{R C}$ and is proportional to the quantity of treated waste:

$$
C_{R C_{t}}=\sum_{R} p_{r}^{0} \sum_{I} \sum_{J} \sum_{A} m_{a, r}^{0} \cdot y_{a, i, j, t}\left(q_{i, t}-u_{t}^{+}\right), t \in T
$$

Equations (15) and (16) define the costs of pollution and resource consumption and introduce non-linearity into the optimization model. To linearize it, additional variables $u_{t}^{+}$and $u_{t}^{-}$that are introduced in Eqns. (18) and (19) are used to determine which of the quantity of generated waste, $q_{i, t}$, or the capacity of the system, $x_{j, l, t}$, is smaller. The constraint in Eq. (17) ensures that the waste from WGS, $i$, assigned and transported to technology, $a$, at candidate site, $j$, at period, $t$, cannot be greater that the capacity of this technology, i.e., $\sum_{i} q_{i, t}-\sum_{J} \sum_{L} x_{j, l, t}$ is equal to zero when $q_{i, t}>x_{j, l, t}$ :

$$
\begin{gathered}
\sum_{i} q_{i, t}-\sum_{J} \sum_{L} x_{j, l, t}=u_{t}^{+}-u_{t}^{-}, t \in T \\
0 \leq u_{t}^{+} \leq M v_{t}, t \in T \\
0 \leq u_{t}^{-} \leq M\left(1-v_{t}\right), t \in T
\end{gathered}
$$


In addition, the amount of waste sent to a given treatment facility cannot be greater than the installed capacity:

$$
\sum_{I} y_{a, i, j, t} q_{i, t} \leq k_{a}^{0} \sum_{L} x_{a, j, l, t}, a \in A, j \in J, t \in T
$$

The waste generated at WGS $i$ cannot be sent to a candidate site $j$ where the WTF has not been installed yet Eq. (21). Also, to limit the number of transportation flows, the waste from one WGS, $i$, can be transported to one and only one candidate site Eq. (22):

$$
\begin{gathered}
y_{a, i, j, t} \leq x_{a, j, l, t}, l=0, a \in A, i \in I, j \in J, t \in T \\
\sum_{J} y_{a, i, j, t}=1, a \in A, i \in I, j \in J, t \in T
\end{gathered}
$$

Eq. (23) shows that the capacity deployment of technology, $a$, at each candidate site, $j$, is progressive. Eq. (24) ensures that the installed capacity cannot be reduced throughout the time:

$$
\begin{gathered}
x_{a, j, l-1, t} \leq x_{a, j, l, t}, a \in A, j \in J, l \in L, t \in T \\
x_{a, j, l, t-1} \leq x_{a, j, l, t}, a \in A, j \in J, l \in L, t=1, \ldots, T
\end{gathered}
$$

It should be noted that the land surface available in each candidate site and its price can be defined by the decision maker in the input parameters as the function of maximum possible installed capacity. For each technology type, $a$, and at each time step, $t$, the total installed capacity cannot exceed the limitation of land space reflected by the total number of possible waste treatment units which can be hosted by each candidate site, $j$ :

$$
\sum_{L} x_{a, j, l, t} \leq K_{a, j}, a \in A, j \in J, t \in T
$$

\subsection{Multi-dimension assessment of WtEMS}

Although the economic performance remains dominant for WtEMS design optimization, other key performance indicators (KPI) must be taken into consideration in the selection of the optimal WtEMS architecture. Until now, the amount of $\mathrm{CO}_{2}$ emissions generated by the new waste treatment strategy played the role of this additional non-economic KPI able to evaluate WtEMS sustainability. However, with the progressive shift toward the combined centralizeddecentralized strategy, WtEMS becomes an inherent part of the urban environment and warrants a more extended multi-dimensional assessment framework.

The proposed multi-dimensional framework supports the decision-maker in evaluating the WtEMS optimality from the point of view of: 
- Deployed capacity. The technological specifications of waste treatment technologies allow their deployment by unit blocks of predefined capacities. In this regard, large centralized facilities are typically composed of "building blocks" of several dozens or hundreds of tons per day capacities. Under some conditions, the optimization model can lead to an important capacity over-deployment to cover the total MSW generation. This overdeployment can create undesirable "lock-in" effects, when the large capital investments but relatively low capital and operating costs can push higher-valued mechanisms of waste recycling (e.g., DF) out of the market [42]. The effectiveness of capacity usage can be quantified through the capacity utilization rate [43] or over-deployment rate as follows:

$$
u=1-\frac{\sum_{t} \sum_{I} q_{i, t}}{K^{\Sigma}}
$$

where $K^{\Sigma}$ is the total deployed waste treatment capacity. The parameter, $u$, takes its value from the range of $[0-1]$ and tends to zero with increasing capacity usage effectiveness. It is noteworthy that, at the same time, the over-deployment rate represents a reserve capacity that can be useful to deal with uncertainties in waste generation.

- Reserved land. Land use required for the waste treatment facilities deployment can become a critical asset not only in the context of land-constrained territories, such as Singapore and Hong Kong, but also large mega-cities. Indeed, efficient land allocation between municipal activities represents a major challenge in the context of rapidly growing cities [44]. In this regard, the decision-maker must be able to select WtEMS in order to avoid large land occupation at one candidate location and ensure the optimal dispersion of waste treatment capacities across urban territories. Indeed, the capacity dispersion can offer important advantages. The spatial spread of WTF can minimize potential risks due to facility failures, ensure a presence of WTF in different urban districts, and provide a uniform waste distribution across all urban territories. To evaluate this capacity dispersion, the indicator of urban fragmentation index [45] is converted into a capacity-land fragmentation factor as follows:

$$
F=\frac{\sum_{J} \sum_{A} \sum_{L} k_{a, j}^{\Sigma} \cdot s_{j, a, l}^{2}}{K^{\Sigma} \cdot S^{2}}
$$

where $s_{j . a, l}$ is the land surface occupied by unit, $l$, of technology, $a$, at candidate site, $j$. Variable $k_{a, j}^{\Sigma}$ is the total waste treatment capacity of technology, $a$, deployed at candidate site, $j$, and $S$ is the total surface of case study. Variable $F$ takes its value from the range of $[0-1]$ and tends to zero in case of high capacity-land fragmentation across urban territories.

Of note, this KPI equips the decision-maker with information regarding land occupation required for WtEMS deployment. Its values must be analyzed individually for each 
particular urban territory, since the decision-maker can aim for low or high capacity-land fragmentation for different urban situations. For example, for dense or land-constrained areas, it can be assumed that a big land portion, i.e., for CF, can be inconvenient. The more feasible alternative is instead to have more dispersed land occupation, i.e., with DF, when the KPI of land-capacity fragmentation will decrease. However, a small KPI may nonetheless generate urban planning challenges since it will imply the need to earmark numerous lots of small land parcels in the city. In this view, the final analysis about the suitability of the WtEMS design based on this KPI must involve urban planners.

- Pressure on the transportation network. Another important KPI concerns the pressure exerted by the WtEMS on the existing urban transportation system. Indeed, detailed evaluation and optimization of the waste transportation routine is typically performed after the problem of WtEMS capacity allocation. The transportation cost is considered in the WtEMS capacity allocation problem; however, this does not enable evaluating the pressure applied by the waste transportation fleet on the urban mobility network. In this view, the additional KPI on the waste transportation fleet has been included in the multi-dimensional assessment framework. The pressure on the transportation network is evaluated through an average number of trucks per day required to transport the MSW from generation source, $i$, to candidate site, $j$. It has been calculated based on the results from the optimization model regarding the waste assigned from WGS to WtE facility by using Eq. (11). This indicator gives a first approximation about the fleet size required for waste transportation; however, the number of trucks can be further optimized with geographical information system models for waste collection.

- Global Warming Potential. A carbon emission tax is included in the optimization OPEX for the process and transportation impact. However, pollutant emissions may originate from other waste treatment related processes, e.g., electricity and material consumption, which are not considered in the economic model. In addition, carbon value can be defined based on different economic mechanisms and different criteria across countries. Indeed, one of the major bottlenecks of a carbon tax is related to the difficulty of estimating the real costs of carbon emissions for the environment. The amount of equivalent pollutants from different MSW management strategies was evaluated in terms of their global warming potential in tons of $\mathrm{CO}_{2}$ equivalent emitted throughout the system lifecycle under consideration:

$$
\begin{aligned}
G W P=365 \cdot & \sum_{T} \sum_{J} \sum_{A} k_{a, j, t} \cdot G W P_{a}^{\text {treat }} \\
& +\sum_{T} \sum_{I} \sum_{J} \sum_{A}\left\lceil\frac{a_{i, j, a, t}}{k^{2}}\right\rceil D_{i, j} \cdot G W P^{\text {transp }}
\end{aligned}
$$


where $k_{a, j, t}$ is the waste treatment capacity of technology, $a$, deployed at candidate site, $j$, at time period, $t$. Variable $a_{i, j, a, t}$ is the amount of waste transported from WGS, $i$, to the technology, $a$, located at candidate site, $j$, per time period, $t$. Variables $G W P_{a}^{\text {treat }}$ and $G W P^{\text {transp }}$ are the amounts of equivalent $\mathrm{CO}_{2}$ emissions associated with operation of waste treatment technology, $a$, and waste transportation, respectively.

As mentioned in Section 17, these factors are already indirectly accounted for in the optimization model through cost functions, i.e., the technology unit, land rental, transportation and emission costs. However, the associated prices cannot fully reflect the importance of these factors. For example, land rental reflects the actual land value but does not allow the direct evaluation of land scarcity. The transportation cost provides estimations of transportation fleet maintenance and fuel cost but does not provide estimations of the pressure exerted by the waste transportation fleet on urban mobility. Therefore, in assessing the WtEMS optimality, the decision-maker needs to assess these additional factors independently from the purely economic-based optimization. To this end, this paper proposes a multi-dimensional assessment framework for the decision-maker after the optimization model has identified the economically-optimal solution.

4. WtEMS in Singapore - waste distribution modeling, system deployment optimization, and design evaluation

This section provides a demonstration of the complex integrated methodology presented in Section 11. It mirrors each subsection to present the outputs and analysis for Singapore based on publicly available information for MSW distribution modeling, WtEMS optimization, and multi-criterion assessment.

\subsection{MSW distribution modeling}

\subsubsection{Urban area profiling and MSW distribution results}

By relying on Singapore's 2011 land-use plan [46] that shows subzone activities with the administrative subdivisions of Singapore, the island activities have been classified into five different categories: Residential (R), Nature (N), Commercial (C), Industrial (I), and Other (O) (Figure 6). The "Other" category consists of special use, infrastructure and areas reserved for further development. As shown in Figure 6, certain subzones can fall into more than one category due to their diverse land use; such subzones are labeled as Mixed (M). 


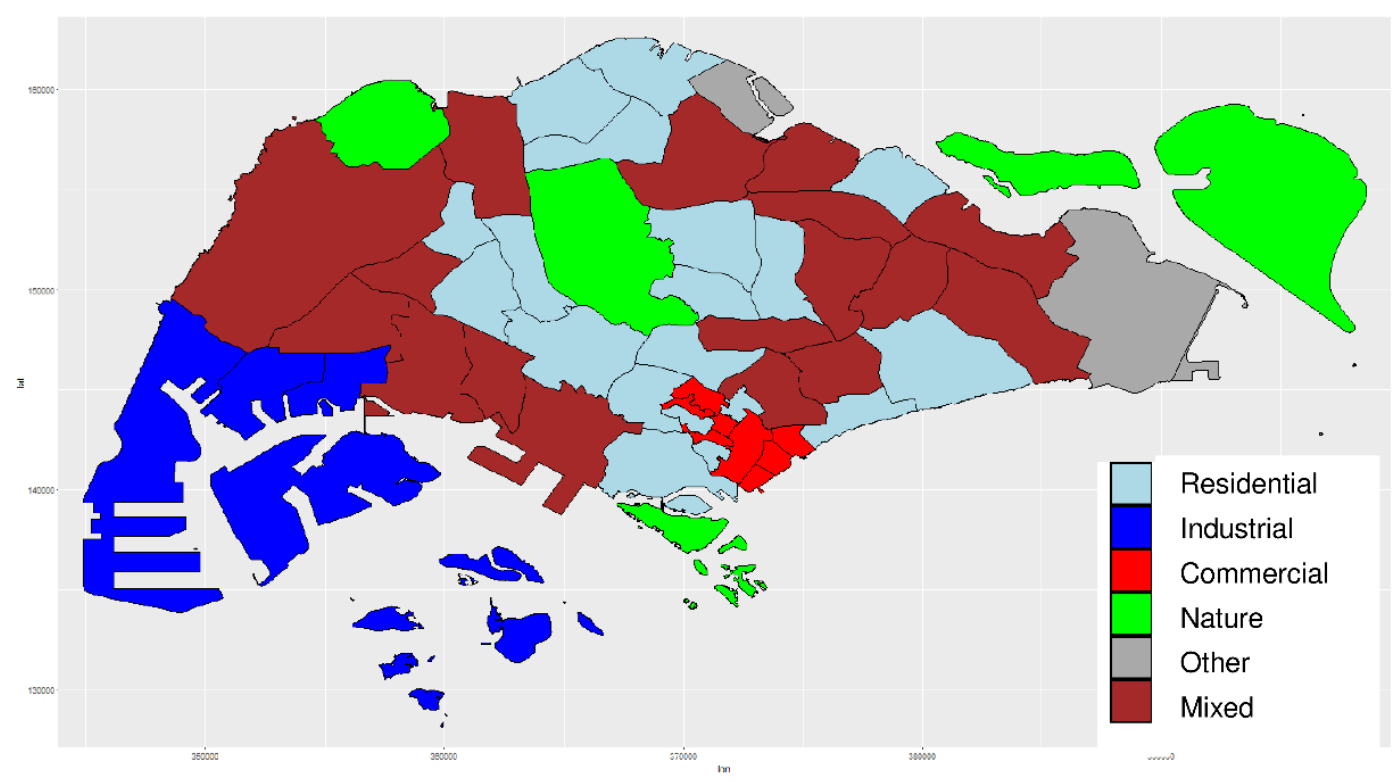

Figure 6. Singapore administrative subzones classification.

The assignment of land subzones to specific categories (e.g., residential, industrial) has been done based on a detailed review of all subzone activities, in addition to the [46] map that gives a broad and simplified view and the particular assumptions of the land space these activities occupy. In other words, to some extent, all subzones will include residences, parks, infrastructure installations, and businesses, which makes all subzones mixed by default. However, the goal of this paper is to make a first step toward a "geography of waste" concept and to model waste distributions only from the major waste contributors in each subzone. To identify dominant activities in each subzone, an occupation threshold has been fixed. If land space occupied by an activity in the specific subzone exceeds this threshold, this activity is qualified to be one of the major ones in this subzone. If the subzone accounts for two or more dominant activities, it is qualified as mixed; otherwise, it is qualified according to its major dominant activity. Figure 6 has been generated with the threshold of $20 \%$ of land occupation by activity by subzone.

Table 4 shows the MSW profiling based on its possible sources.

Table 4. Waste type profiles.

\begin{tabular}{|l|l|l|l|}
\hline Waste Type & Examples & Possible Sources & Classification \\
\hline Construction Debris & Unwanted material from constructions & Construction Sites & Non-Domestic \\
\hline Used Slag & Waste matter from smelting & Steel Mills & Non-Domestic \\
\hline Ferrous Metals & Steel Cans, Aluminum & Households, Factories & Mixed \\
\hline Wood/Timber & Pallets, Furniture, Crates & Households, Factories & Mixed \\
\hline Horticultural Waste & Tree trunks, Branches & Maintenance of trees & Non-Domestic \\
\hline Paper/Cardboard & Books, Boxes & Households, Offices, Factories & Mixed \\
\hline Food Waste & Meat, Fish, Vegetables & Households, Restaurants & Mixed \\
\hline Plastics & Plastic bottles, Plastic bags & Households, Offices & Mixed \\
\hline Others & - & - & Mixed \\
\hline
\end{tabular}


Following this waste profiling, Table 5 identifies the type of waste based on its possible sources, depending on the subzone classification.

Table 5. Waste type subzone classification

\begin{tabular}{|l|c|c|c|c|c|}
\hline \multirow{2}{*}{ Waste Type } & \multicolumn{5}{|c|}{ Subzone Classification } \\
\cline { 2 - 6 } & Residential & Commercial & Industrial & Nature & Others \\
\hline Construction Debris & $\mathrm{X}$ & $\mathrm{X}$ & $\mathrm{X}$ & & $\mathrm{X}$ \\
\hline Used Slag & & & $\mathrm{X}$ & & $\mathrm{X}$ \\
\hline Ferrous Metals & $\mathrm{X}$ & $\mathrm{X}$ & $\mathrm{X}$ & & $\mathrm{X}$ \\
\hline Wood/Timber & $\mathrm{X}$ & $\mathrm{X}$ & $\mathrm{X}$ & & $\mathrm{X}$ \\
\hline Horticultural Waste & $\mathrm{X}$ & $\mathrm{X}$ & $\mathrm{X}$ & $\mathrm{X}$ & $\mathrm{X}$ \\
\hline Paper/Cardboard & $\mathrm{X}$ & $\mathrm{X}$ & $\mathrm{X}$ & & $\mathrm{X}$ \\
\hline Food Waste & $\mathrm{X}$ & $\mathrm{X}$ & $\mathrm{X}$ & & $\mathrm{X}$ \\
\hline Plastics & $\mathrm{X}$ & $\mathrm{X}$ & $\mathrm{X}$ & & $\mathrm{X}$ \\
\hline Others & $\mathrm{X}$ & $\mathrm{X}$ & $\mathrm{X}$ & $\mathrm{X}$ & \\
\hline
\end{tabular}

The above tables offer insights into the assignment of waste to the different subzones. The classification of the areas was done using qualitative online research and analysis of the land use plan. Categories of land activities present in the administrative subzones are given a score of 1 while those absent are given 0 . Based on this analysis, mixed subzones involving more than one activity have been assigned a score between 0 and 1 based on the land space percentage occupied by each activity in each administrative subzone. For this purpose, Singapore's land development plan has been used. Attention should be drawn to the possibility that these scores can be adjusted to reflect different activity densities, e.g., the population density in the respective residential sectors and intensity of commercial activities.

Figure 7 gives an overview of the available statistical data for waste generation in Singapore from 2003 to 2015 . The available data was used to obtain a fixed percentage ratio for waste types falling in both categories. The percentages of domestic and of non-domestic wastes for mixed waste types were estimated to be 60.85 and $39.15 \%$, respectively. 


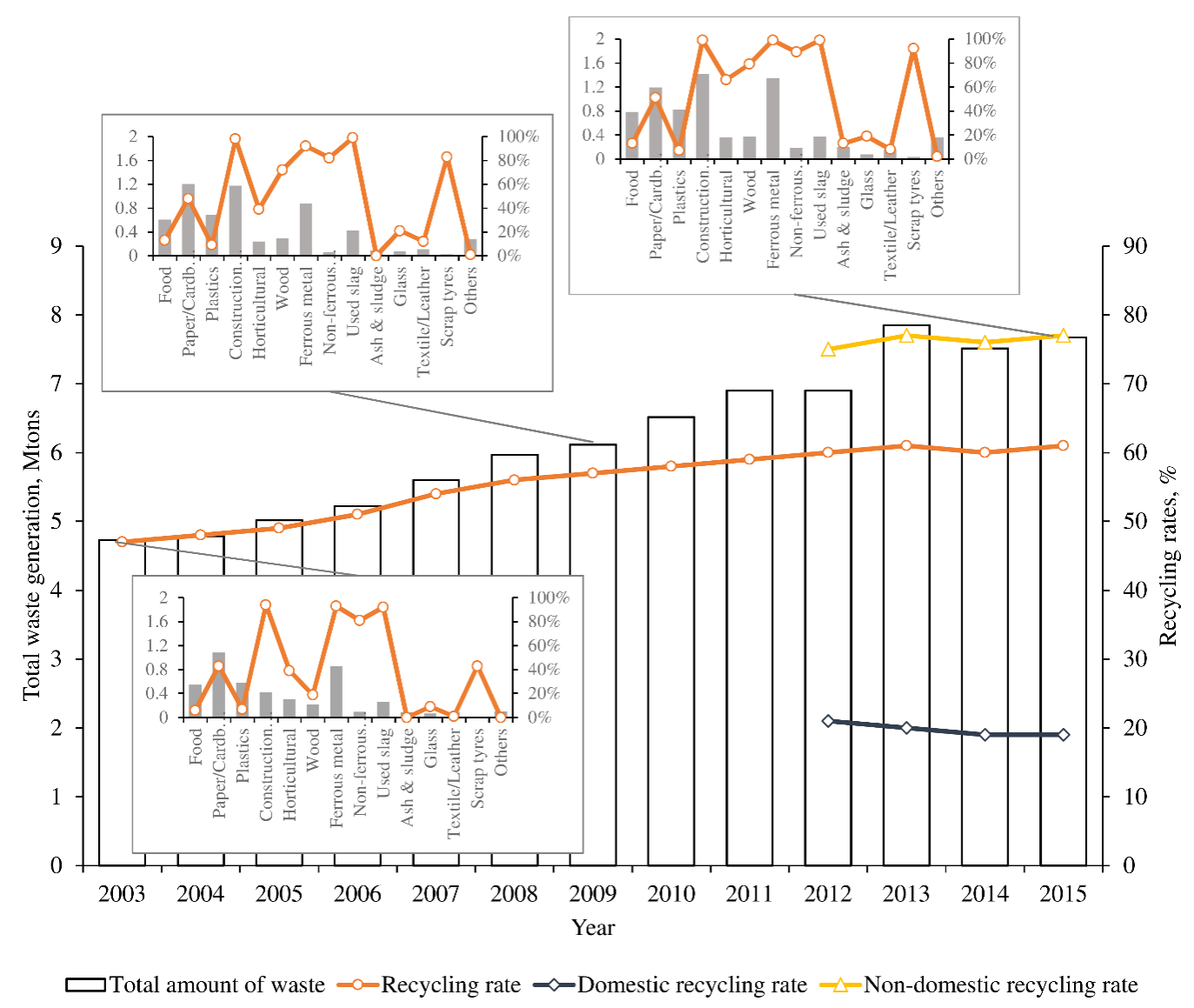

Figure 7. Statistical data overview for MSW generation evolution and recycling rates in Singapore from 2003 to 2015 [47].

Figure 8 depicts the example of food waste distribution across Singapore in 2015.

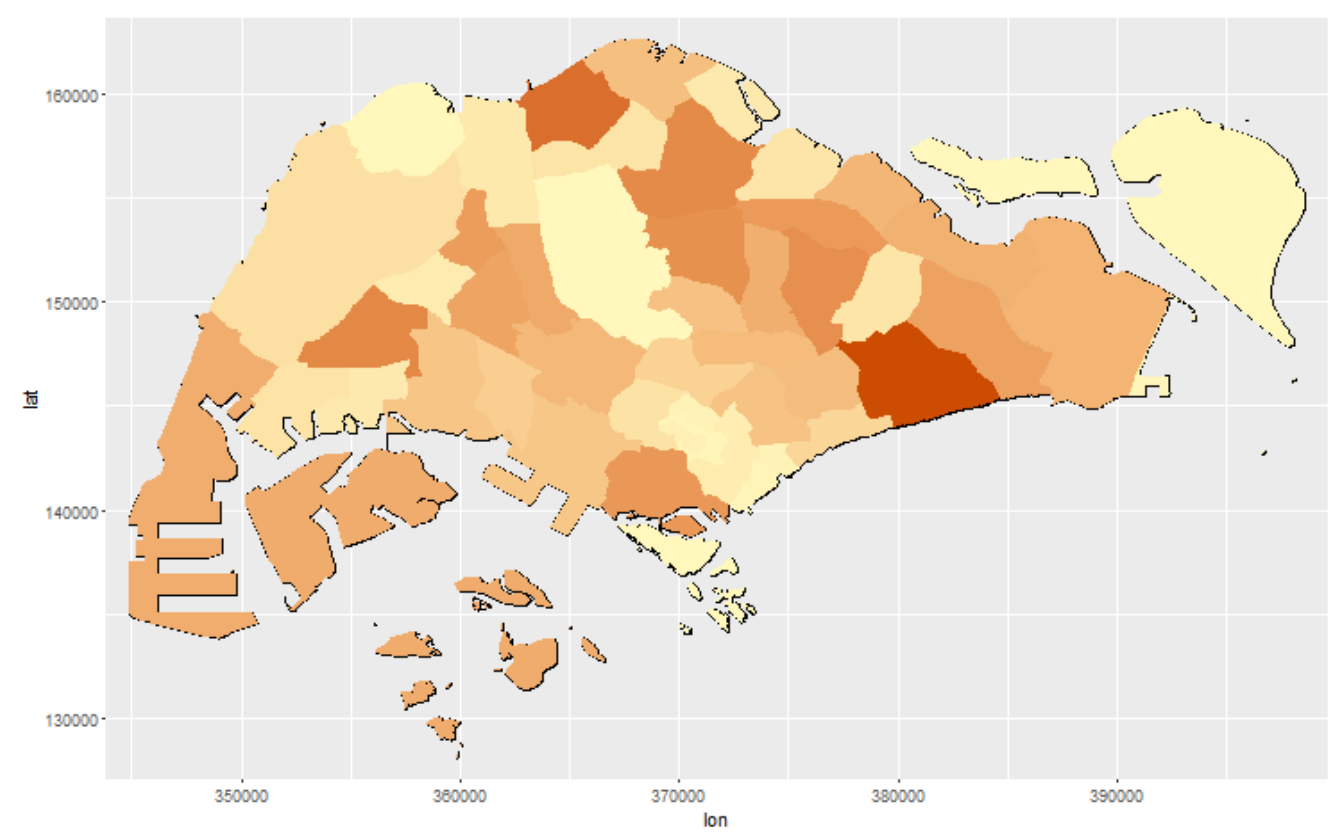


The major sources of food waste generation have been estimated to be Bedok, Woodlands, and Jurong West with 5.9, 5.1, and 4.8\% of the total Singapore food waste output, respectively (Figure 11(c)). The highly dense residential areas involve a high number of markets, food centers, and restaurants responsible for the considerable food waste generation.

\subsubsection{MSW model analysis}

While the calculation based on land area and population may be logical for domestic and nondomestic waste generation, it may present some drawbacks.

Firstly, the MSW distribution model considers only basic geographical and demographic attributes. However, more accurate MSW distribution modeling requires more data related to different subzones activities. By considering this, subzones situated remotely from residential areas could be less frequented and may generate less MSW than remote areas holding attraction elements. Accordingly, hotspot places such as Tampines with many conveniently located shopping malls or Geylang with nightlife activities could hold an increased human traffic and, thus, increased waste generation. In addition, the types of waste generated during day and night times can vary. Accordingly, a modifier matrix becomes important to encompass such social and economic parameters in the MSW distribution model. A possible contribution could be in the MSW modeling distribution and urban development areas in order to quantify the attractiveness of different urban areas and, thus, model their MSW distribution. The modifier matrix can be established based on the centrality index quantifying the centrality of a given location by combining the number of people attracted to locations and the range of their activities engaged at these locations [48].

Secondly, the MSW distribution uses 12 years of statistical data to obtain the fixed percentage ratios for waste types falling simultaneously in categories of domestic and non-domestic waste. However, for accurate waste profiling, a more detailed analysis is required of the waste categories and activities sources. This work can be done in collaboration with local authorities by holding survey campaigns for waste generation and collection.

Moreover, MSW distribution modeling is based on fixed 2015 population census data and land area subzones for weight calculations. In this view, the weights for each subzone will be constant and not change over time. One possible improvement would be to link the MSW distribution model to the prediction of explanatory variables to determine the evolution in domestic and non-domestic MSW. For example, the growth of a subzone population based on projects for development of residential areas or the extent of industrial development based on the opening of new industrial sites could be considered.

\subsection{WtEMS design optimization}

\subsubsection{Optimization model input}

The optimization model can exploit the output of the MSW distribution modeling (Section 24) or the specific information of MSW generation provided by a decision-maker. For simplicity, the proposed methodology has been illustrated here through one stream of food waste 
representing an important portion of the world MSW [49]. The disposal rate of food waste reaches almost $86 \%$ for Singapore [47].

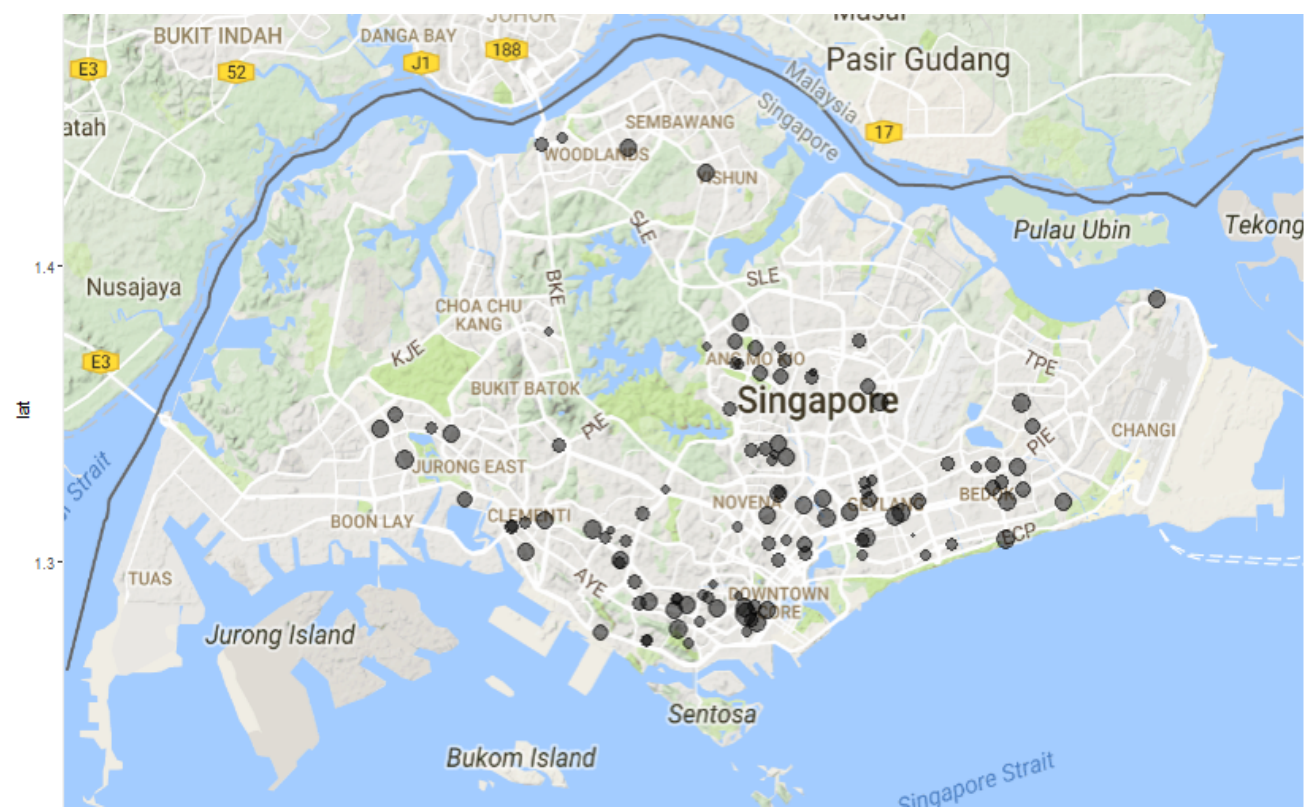

Figure 9. Food WGS established on the Google Map representation of Singapore.

For the purpose of this study, the WGS have been represented by the nodes of food waste generation in 111 food courts, hawker centers, and markets across Singapore. To estimate the amount of food waste produced daily by each hawker center, waste generation data have been collected in several targeted sources. By using this data, as well as WGS area estimation from the GIS software, the average food waste per unit area has been estimated to be $1.409 \mathrm{~kg} / \mathrm{m}^{2}$ per day. Under the assumption that the same food waste amount, $q_{i, t}$, is generated per unit area, the waste output for 111 WGS was estimated (Figure 9). The amount of waste generated at each WGS, $i$, has been assumed to grow linearly over the considered lifecycle with a constant increase of $2 \%$ per year.

Table A1 in Appendix A. Table A1 in 42 summarizes the data related to possible technologies to be deployed at candidate locations. The first prototype of micro-scale AD technology, considered here for the on-site deployment, was built in 2013 in London (UK) to process urban food waste and continues to operate to date [50]. Currently, three similar pilot plants have been established, with two in Central London [51]. The equivalent large scale AD plant has been considered for the off-site deployment [51]. Although, current waste treatment in Singapore mainly relies on incineration, the technical specifications of the benchmark technology have been defined based on open source data for waste-to-energy technology from [52].

Two candidate sites have been preselected for the off-site facilities locations: the reserved construction area in Seletar subzone and the area near the water reclamation plant in Changi. At each candidate site, five AD units can be deployed, subjected to the limitation of available land space. The transportation distances have been calculated between the WGS and these 
candidate sites, i.e., the average distances from the WGS to candidate sites at Seletar and at Changi are $11.6 \mathrm{~km}$ and $17.6 \mathrm{~km}$, respectively.

The candidate sites for on-site DF coincide with WGS coordinates. In this view, no specific transportation efforts are needed to ensure the supply of food waste from the WGS to the DF equipped with micro-scale AD. The land cost is assumed to be $\$ 15 / \mathrm{m}^{2}$ per year for the industrial areas and $\$ 25 / \mathrm{m}^{2}$ per year for residential areas [53]. The $\mathrm{CO}_{2}$ emission tax has been assumed to be $\$ 10$ per ton of $\mathrm{CO}_{2}$ equivalent [54]. The $\mathrm{CO}_{2}$ emissions for food waste transportation has been defined to represent on average $600 \mathrm{~g} \mathrm{CO}_{2}$ per kilometer travelled [55]. The electricity price has been fixed to $\$ 0.15 / \mathrm{kWh}[56]$. The discount rate, EoS factor, and lifecycle duration have been set up to $0.01,0.8$, and 15 year, respectively. The convergence gap has been fixed to $1 \%$.

\subsubsection{WtEMS deployment}

The following figures illustrate a progressive deployment of waste treatment infrastructure for Year 1 (Figure 10(a)), Year 10 (Figure 10(b)), and Year 15 (Figure 10(c)) across Singapore. In addition, they depict the evolution of food waste assignment from the WGS to different WtE CF. The optimization starts with the deployment of AD at Year 1 at both off-site candidate sites of 250 and 200 tons/day capacity, respectively. The capacity at site 2 is expanded at Year 3 up to 250 tons/day. The DF are deployed progressively throughout the lifecycle to treat food waste exceeding the WtE CF capacity.

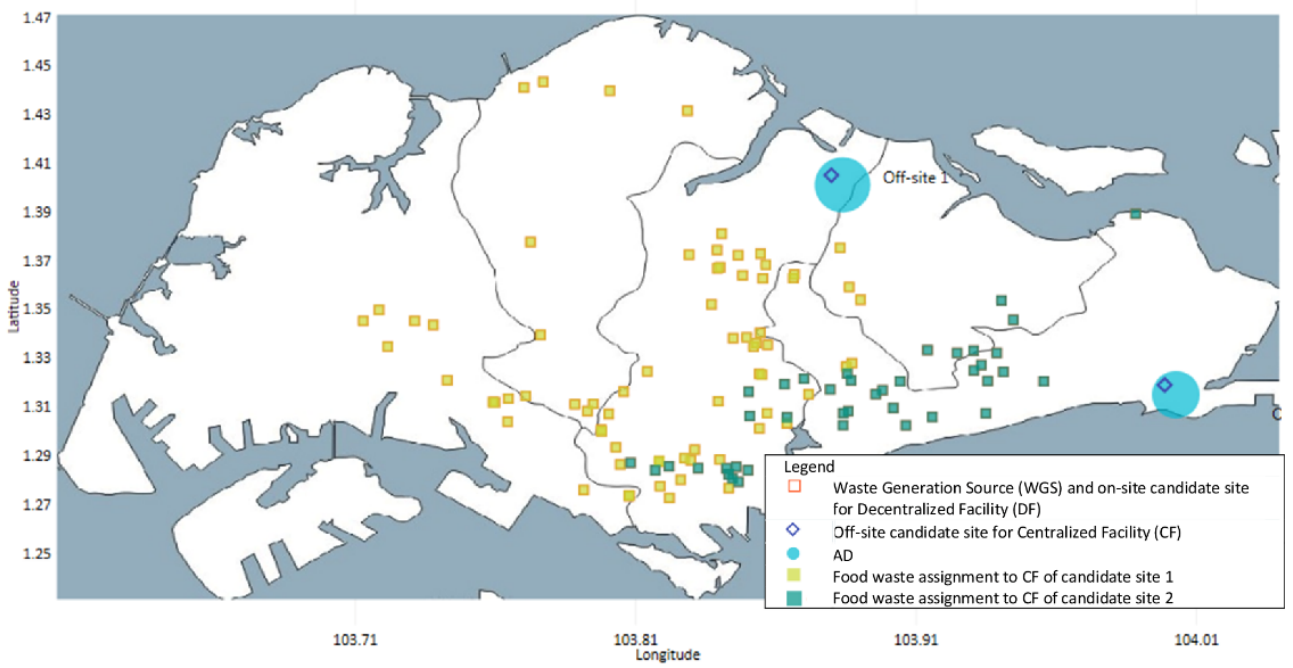

a) 


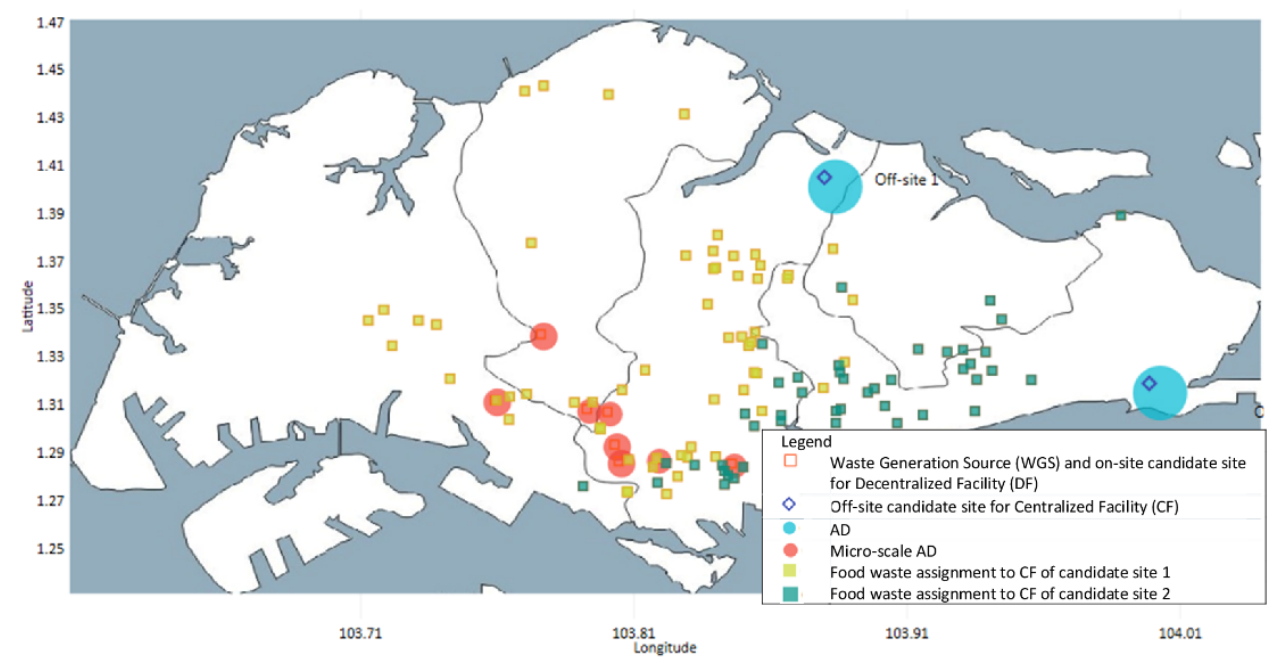

b)

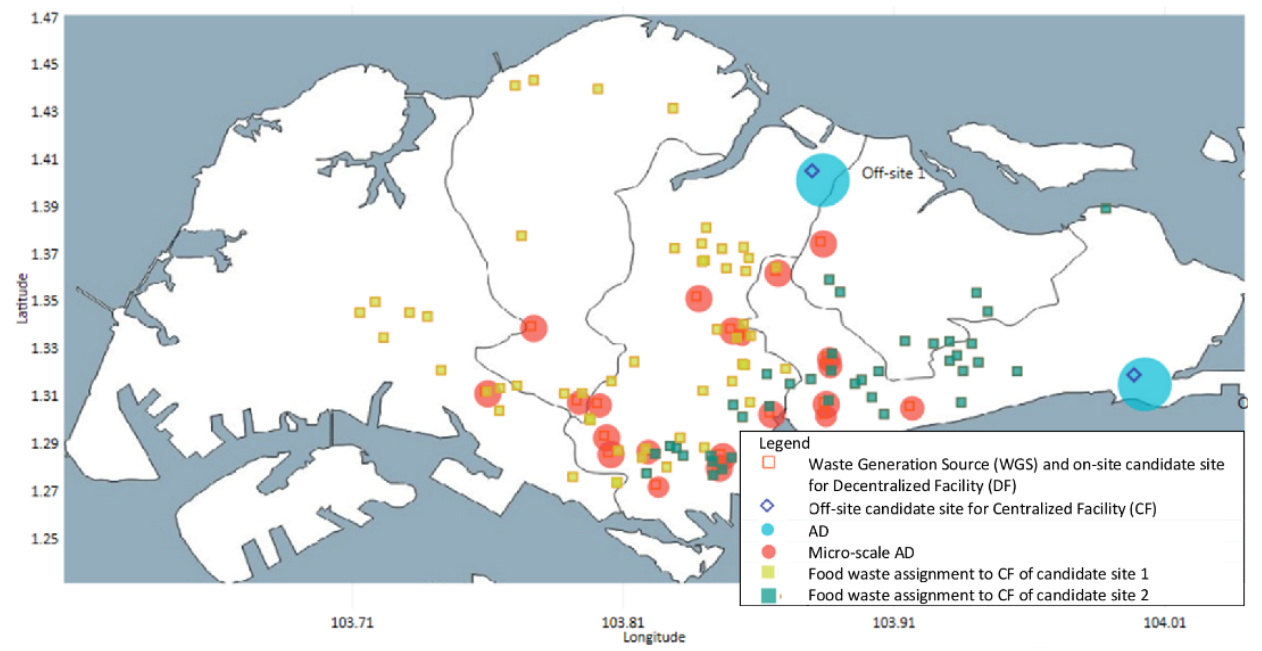

c)

Figure 10. Progressive WtEMS deployment over the lifecycle: a) Year 1, b) Year 10, and c) Year 15.

The deployment strategy is visible from the detailed cash flows distribution for the entire lifecycle (Figure 11(a)). The main CAPEX investment for CF deployment is done in Year 1 and another additional CF unit is deployed in Year 3. The DF starts its deployment in Year 2 to deal with waste exceeding the capacity of the $\mathrm{WtE} \mathrm{CF}$. Following the increase in the food waste generation, a progressive addition of DF treatment capacities continues to be observed in the optimization. The installed capacity proportion of $\mathrm{DF} / \mathrm{CF}$ reaches about $84 \%$ for $\mathrm{CF}$ and $16 \%$ for DF in the final Year 15.

The discounted cash flow distribution of the total lifecycle is illustrated in Figure 11(b). It shows that the major expenses are shared by CAPEX, O\&M, and manpower costs representing $17.5 \%, 31 \%$, and $31 \%$, respectively. Resource consumption and transportation expenses occupy around $11.8 \%$ and $6.8 \%$ of the total lifecycle investment, respectively. At the current levels of carbon price and rent cost, pollution tax and land cost represent $0.4 \%$ and $1.4 \%$, respectively, and are not significant in the decision-making. 


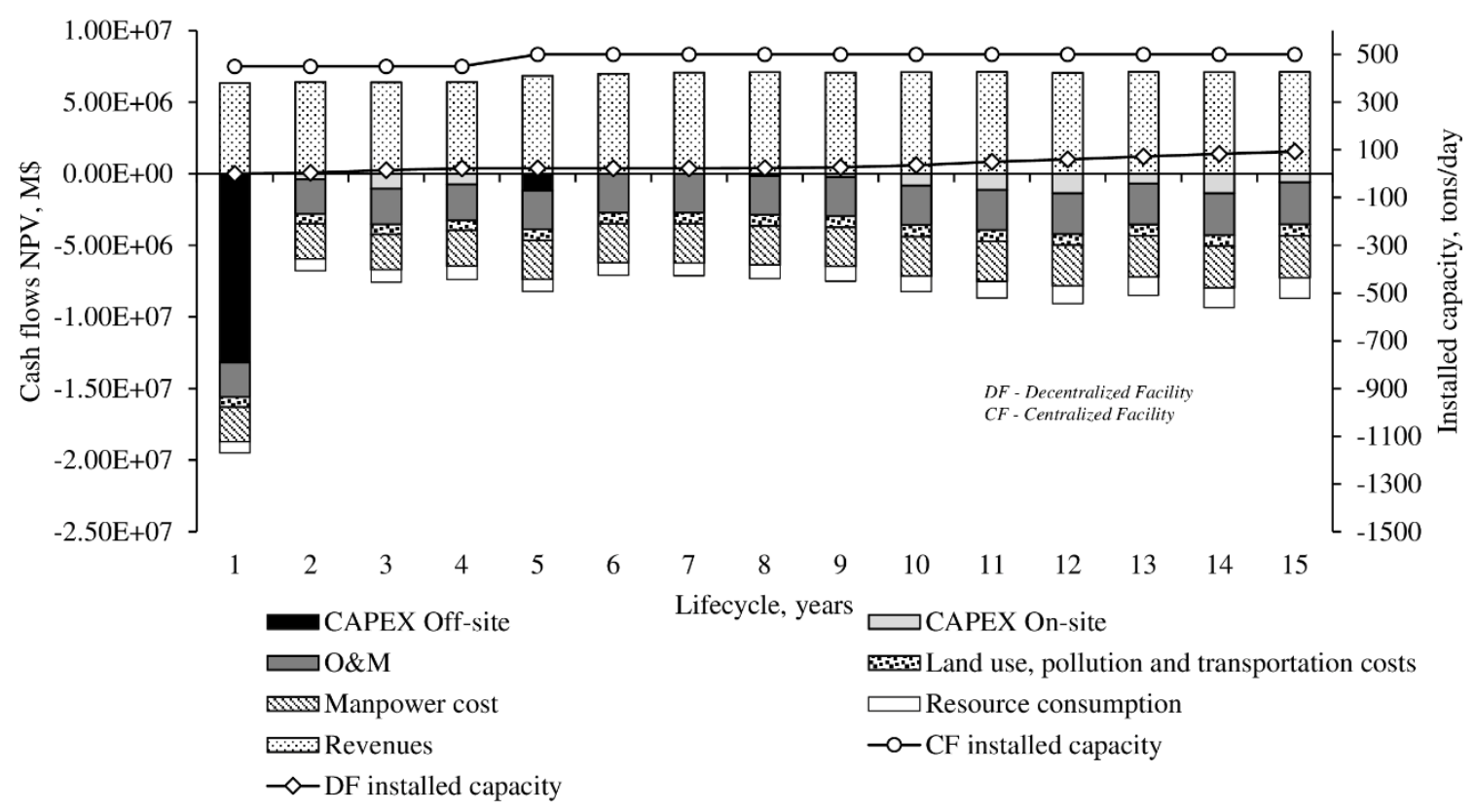

a)

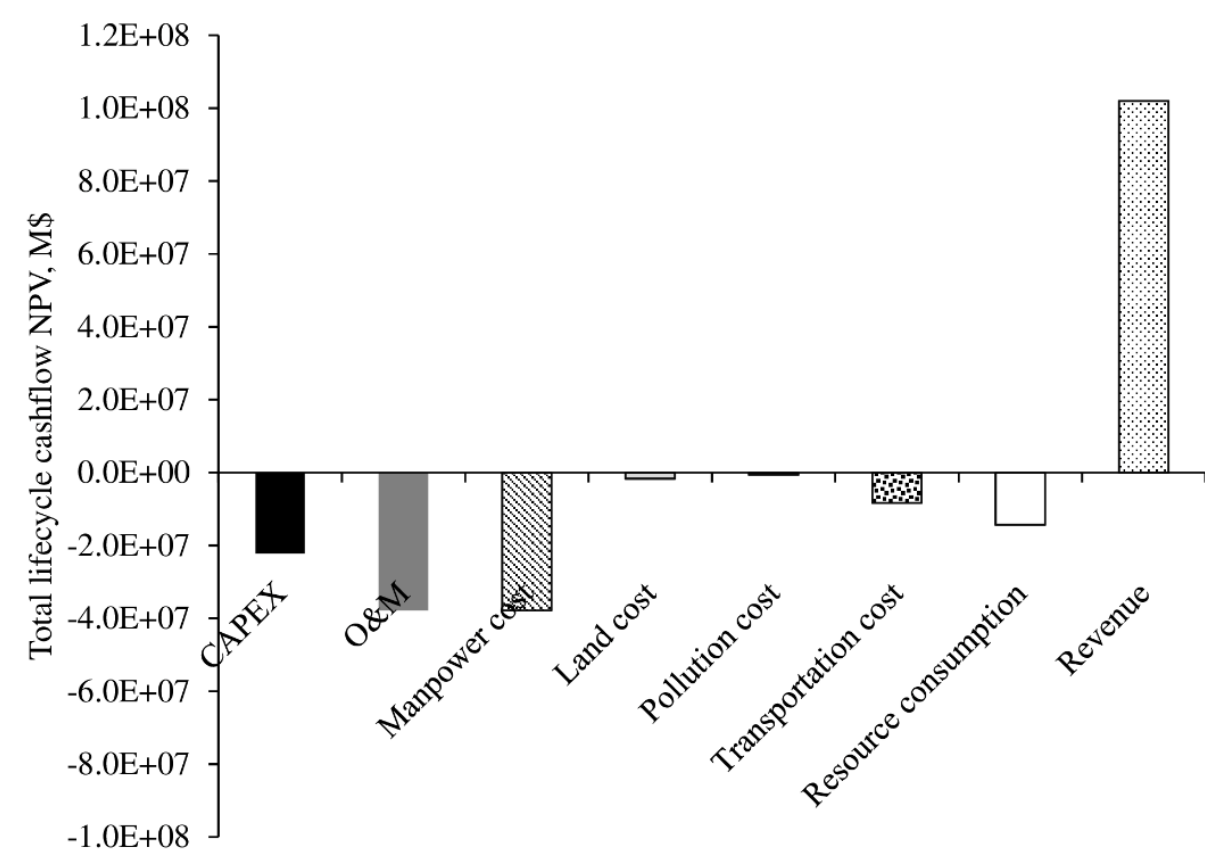

b)

Figure 11. Optimized solution discounted cash flows: a) yearly cash flows and b) total lifecycle cash flows. 


\subsubsection{Sensitivity analysis}

\section{a. EoS impact}

Figure 12(a)-(c) illustrates the WtEMS deployment for different EoS factors. The CF is used to treat the majority of the waste generation whereas the DF are used to adjust the installed treatment capacity to tackle the increase in the waste generation.

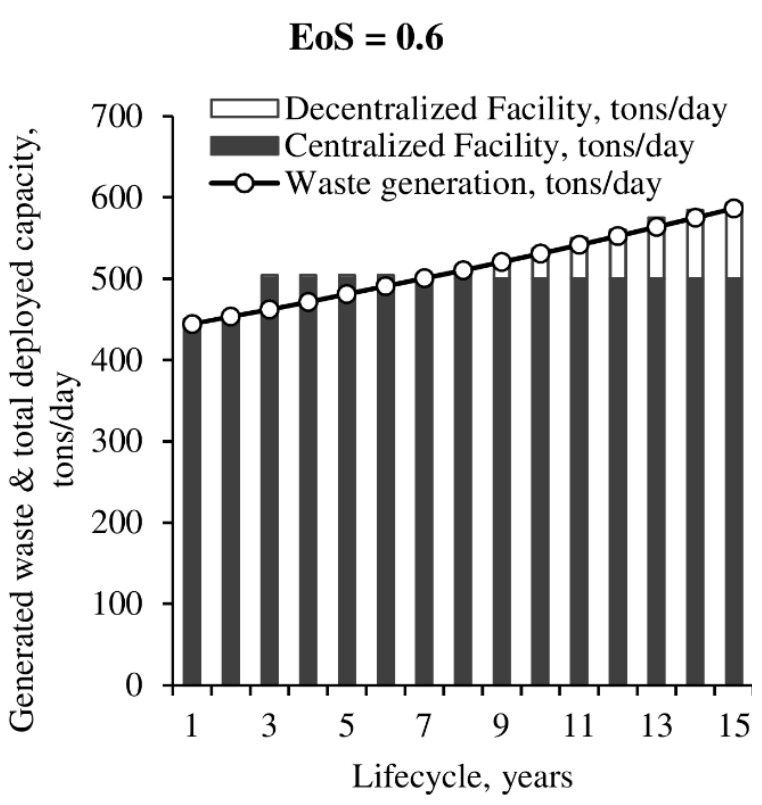

a)

$$
\operatorname{EoS}=0.8
$$

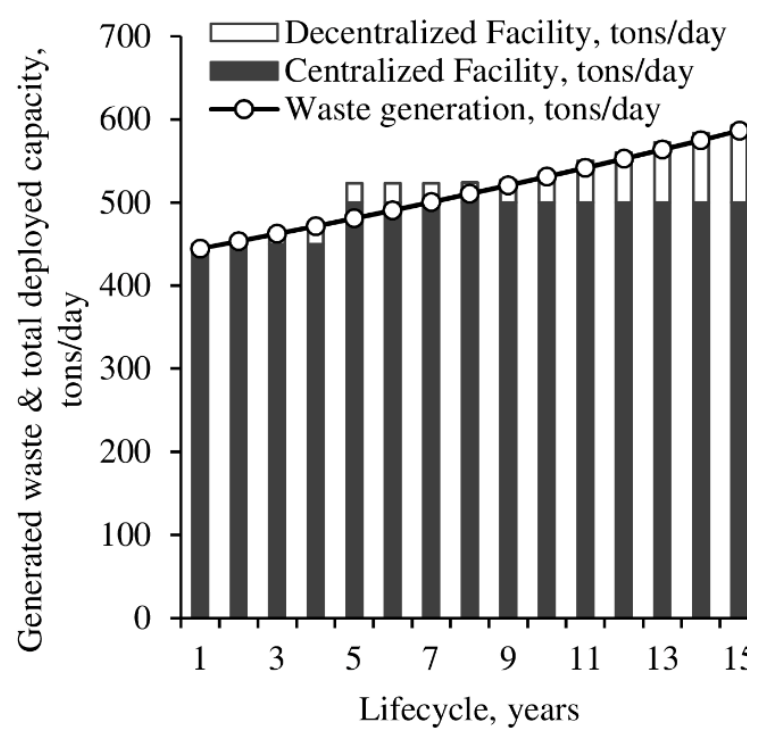

b)

$\operatorname{EoS}=1$

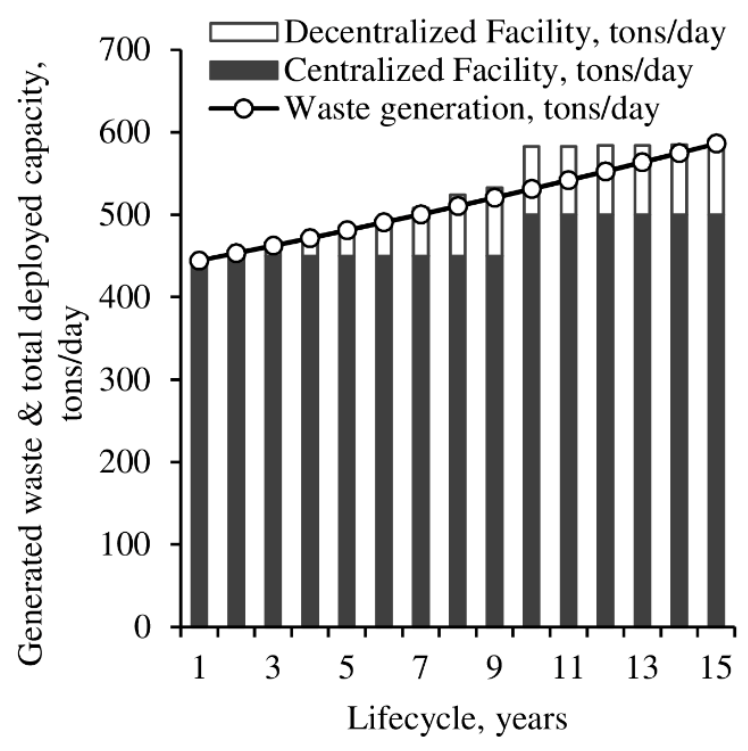

c)

Figure 12. Progressive WtEMS deployment for a) $\operatorname{EoS}=0.6, \mathrm{~b}) \operatorname{EoS}=0.8$, and c) $\operatorname{EoS}=1$. 
This deployment is in line with observations done in [57] for the addition of new capacities under the constant growth of demand and a non-zero discount factor. While decreasing the EoS factor (or reinforcement of EoS) and maintaining the same discount factor, it is preferable to build a large capacity earlier in the planning period, even though operators need to pay immediately for capacity that will only be used later. This is confirmed by the evolution of the over-deployment of the total WtEMS capacity for different EoS factors, as illustrated in Figure 13. The over-deployment peaks are situated in order from $\mathrm{EoS}=0.6$ to $\mathrm{EoS}=1$ during the planning lifecycle.

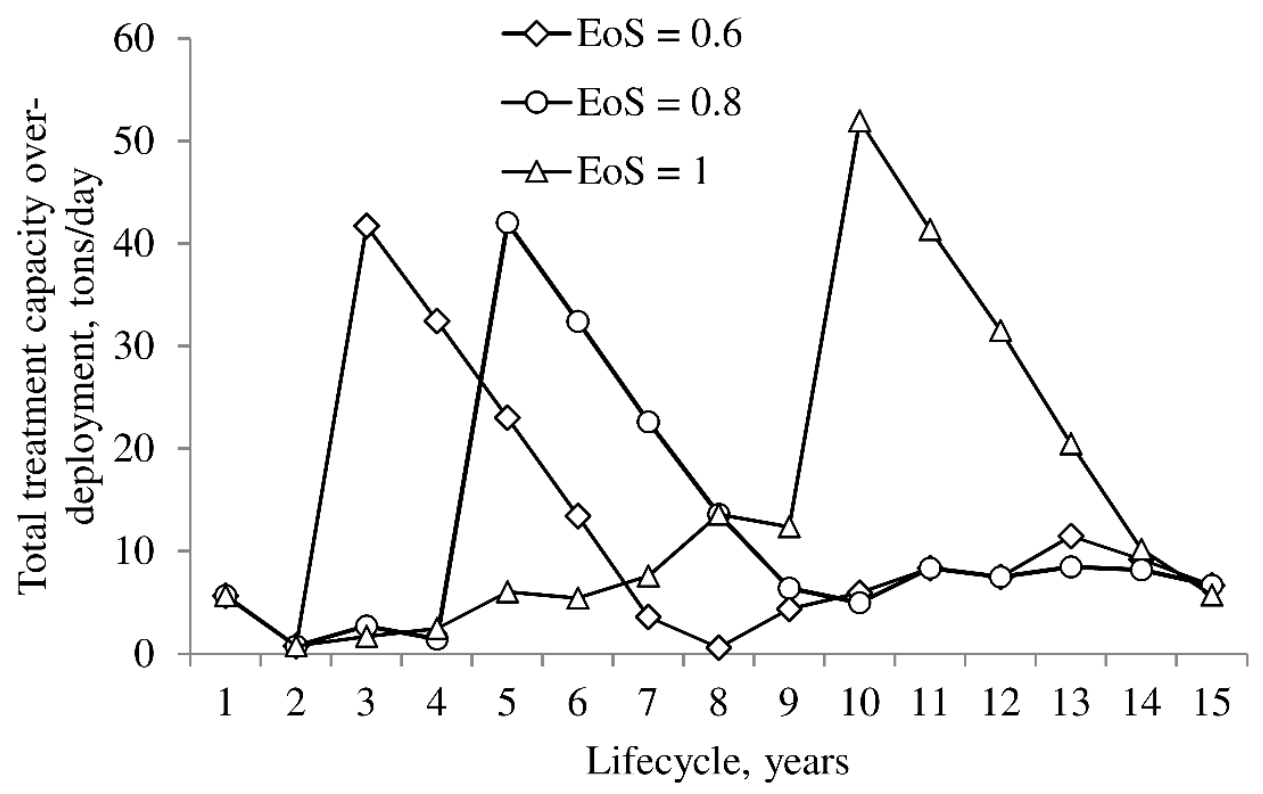

Figure 13. Total WtEMS capacity over-deployment for different EoS factors.

\section{b. Initial capacity input}

An important consideration concerns the selection of parameters used by a decision-maker as input to the optimization model. Such inputs will define an optimized WtEMS configuration regarding the sizes of waste treatment vertexes, such as the WTF capacity and edges length that involves the transportation distance. Indeed, the decision-maker must specify the input parameters related to the capacities of waste treatment units, number of units allowed to be deployed, and candidate sites locations that define the distances between the WGS and WTF.

As shown in Section 30, transportation expenses have a moderate contribution to the total NPV for the case study under consideration. As a consequence, the distance does not exert a significant influence on the deployment results for the case study size similar to Singapore (i.e., several dozens of $\mathrm{km}$ ) at a similar transportation price. In this regard, the decision-maker has the freedom to predefine candidate sites in this perimeter without considerably affecting the final WtEMS configuration. The analysis below focuses on the impact of the initial waste treatment capacities, preselected for deployment by the decision-maker, on the optimized WtEMS configuration. Indeed, even if the producers of the technologies could offer various 
waste treatment capacities, the decision-maker's input is required to be more specific. A large range of preselected capacities can lead to waste treatment technologies of various capacity sizes in the deployment solution, resulting in customized and costly WtEMS. Moreover, some capacity sizes selected for deployment can lead to the decreased effectiveness in capacity usage.

The following analysis shows the influence of the initial CF capacities (defined as inputs by decision-maker) on the proportion of CF- and DF-deployed capacities for EoS $=0.8$ (Figure $14)$.

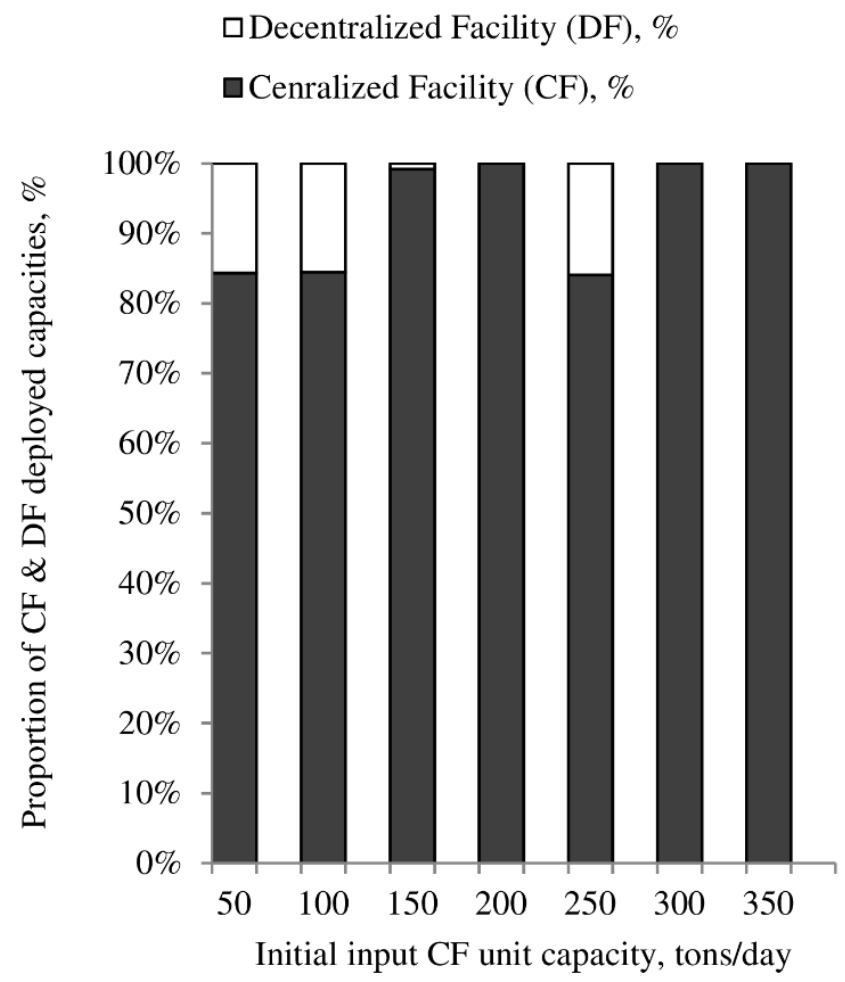

Figure 14. Proportions of CF and DF capacities deployed under different initial input of CF unit capacities.

The WtEMS configuration or CF- or DF-deployed capacities proportions can be affected by the initial input of the CF capacity unit. By minimizing the objective function, the optimization model identifies the optimal WtEMS configurations under different initial input of $\mathrm{CF}$ capacities. In this context, for the initial input of CF capacities is equal to 50, 100, and 250 tons/day, and the total deployed capacity is composed of about $84 \%$ of CF and $16 \%$ of DF facilities. For the initial input of CF capacity equal to 150 tons/day, the deployed DF portion is reduced to about $1 \%$, whereas for the initial input of CF capacity equal to 200,300 , and 350 tons/day, no DF facilities have been deployed.

One possible explanation is related to the fact that the optimization problem searches for the best combination of CF and DF units to address the total waste generation at the most optimal cost. In this view, when the total waste generation exceeds the CF capacity but is insufficient to activate the deployment of another centralized unit, the optimization model deploys a DF to 
cover this outstanding waste generation. Also, with an increase of the initial input to the CF unit capacity, the EoS influence increases as well. This leads to a situation where the optimization model attempts to rely entirely on the centralized deployment. However, this output can change with the modification of costs associated with CF and DF deployment and operation. In this view, the deployment mechanism for the combined centralized-decentralized WtEMS must be further analyzed in detail. Moreover, this mechanism must be accounted by the decision-makers at the early stage prior to the optimization to achieve the optimal balance between centralized and decentralized capacities suitable for the specific urban territory.

The influence of DF capacities on the deployment results for the combined centralizeddecentralized WtEMS has been found to be minor and are therefore not discussed in this paper.

\subsection{Multi-dimensional assessment}

To assess the performance of the optimized deployment strategy integrating both the $\mathrm{CF}$ and DF, the combined WtEMS has been compared with the pure centralized WtE and decentralized MSW management strategies (Table 6). The metrics for the benchmark case, if all generated waste has been processed in the conventional incineration facility, have also been calculated. It was assumed that this conventional treatment is done in the existing facility, which does not require CAPEX investment.

The inputs for the global warming potential (GWP) assessment of different MSW strategies were retrieved from the LCA study by [58] conducted for Singapore. The incineration used for the benchmark was associated with $113 \cdot 10^{6} \mathrm{~g} \mathrm{CO}_{2}$ equivalent/ton of treated waste and the $\mathrm{AD}$ with $83 \cdot 10^{6} \mathrm{~g} \mathrm{CO} 2$ equivalent/ton of treated waste. These values were calculated by taking into account the avoidance factor of electricity generation during waste treatment. The GWP input for transportation activities was estimated to be $1014 \cdot \mathrm{g} \mathrm{CO}_{2}$ equivalent $/ \mathrm{km}$ for a six-ton load truck [58].

Table 6 summarizes the core economic indicators from the optimization (Section 28) and the multi-dimensional assessment for different MSW management strategies based on i) combined centralized-decentralized $\mathrm{WtE}$ facilities, ii) centralized $\mathrm{WtE}$ facilities, iii) decentralized $\mathrm{WtE}$ facilities integrated in the urban environment, and iv) conventional waste treatment by incineration.

Table 6. Comparison of MSW management strategies.

\begin{tabular}{|l|c|c|c|c|c|}
\hline $\begin{array}{l}\text { MSW management } \\
\text { strategies / Parameters }\end{array}$ & Combined & Centralized & Decentralized & $\begin{array}{c}\text { Conventional } \\
\text { treatment (existing } \\
\text { incineration) }\end{array}$ & Best \\
\hline $\begin{array}{l}\text { Total NPV, } \\
\text { M\$/lifecycle }\end{array}$ & -20.82 & -8.82 & -47.57 & - & Centralized \\
\hline $\begin{array}{l}\text { Total NPV CAPEX, } \\
\text { M\$/lifecycle }\end{array}$ & -22.18 & -15.66 & -55.02 & - & Centralized \\
\hline $\begin{array}{l}\text { Total NPV OPEX, } \\
\text { M\$lifecycle }\end{array}$ & -100.64 & -94.9 & -98.55 & -202.8 & Centralized \\
\hline $\begin{array}{l}\text { Total NPV Revenues, } \\
\text { M\$/lifecycle }\end{array}$ & 102 & 101.74 & 106 & 50.87 & Decentralized \\
\hline $\begin{array}{l}\text { Average capacity over- } \\
\text { deployment rate }\end{array}$ & 0.022 & 0.055 & 0.11 & $-(1)$ & Combined \\
\hline
\end{tabular}




\begin{tabular}{|l|c|c|c|c|c|}
\hline $\begin{array}{l}\text { Total reserved land, } \mathrm{m}^{2} \\
(2)\end{array}$ & $\begin{array}{c}11,860(84.32 \% \text { for CF } \\
\text { and } 15.68 \% \text { for DF })\end{array}$ & 12,000 & 12,860 & 12,000 & Combined \\
\hline $\begin{array}{l}\text { Land-capacity } \\
\text { fragmentation }\end{array}$ & $4.09 \cdot 10^{-12}$ & $1.62 \cdot 10^{-11}$ & $1.98 \cdot 10^{-13}$ & $1.62 \cdot 10^{-11}$ & $\begin{array}{c}\text { Decentralized } / \\
\text { Combined }\end{array}$ \\
\hline $\begin{array}{l}\text { Average transportation } \\
\text { fleet, trucks }\end{array}$ & 72 & 85 & - & 85 & Decentralized \\
\hline $\begin{array}{l}\text { Global Warming } \\
\text { Potential, Mtons } \\
\mathrm{CO}_{2} / \text { lifecycle }\end{array}$ & 238 & 245.4 & 254.8 & 292.75 & Combined \\
\hline
\end{tabular}

(1) Capacity over-deployment for the conventional treatment could appear if currently installed capacity is insufficient to handle the increase in food waste generation and will depend on the capacity of incineration unit assumed for plant expansion.

(2) Average land use does not take into account the land use by auxiliary installations and equipment (e.g., warehouse, office).

The centralized WtEMS shows good performance in the economic KPI. It requires the lowest CAPEX and OPEX over the planning horizon. In comparison, the deployment of the combined WtEMS incurs more expenses and, as a result, the Total NPV more than doubled in comparison with that of the centralized waste management strategy. The decentralized WtEMS requires important Total NPV related to the deployment of multiple stand-alone facilities and associated infrastructures for local waste treatment. However, it shows slightly higher revenues than the centralized and combined cases due to its slightly better transformation efficiency. All three strategies based on the AD technology perform better than the conventional incineration. More specifically, the proposed combined WtEMS reduces OPEX by half and more than doubles revenues in comparison with conventional MSW treatment.

The combined centralized-decentralized case outperforms other waste management strategies in terms of over-deployment of the average capacity, total land surface reserved for treatment facilities, and environmental impact. Indeed, the combined WtEMS allows the optimal combination of large centralized units with micro-scale decentralized facilities. This desirably leads to the minimum rate of the total capacity of over-deployment and land occupation. In addition, the combined WtEMS reduces GWP by about $18.7 \%$ in comparison with the conventional strategy and performs slightly better than the purely centralized and decentralized strategies due to the minor over-deployment in capacity. 


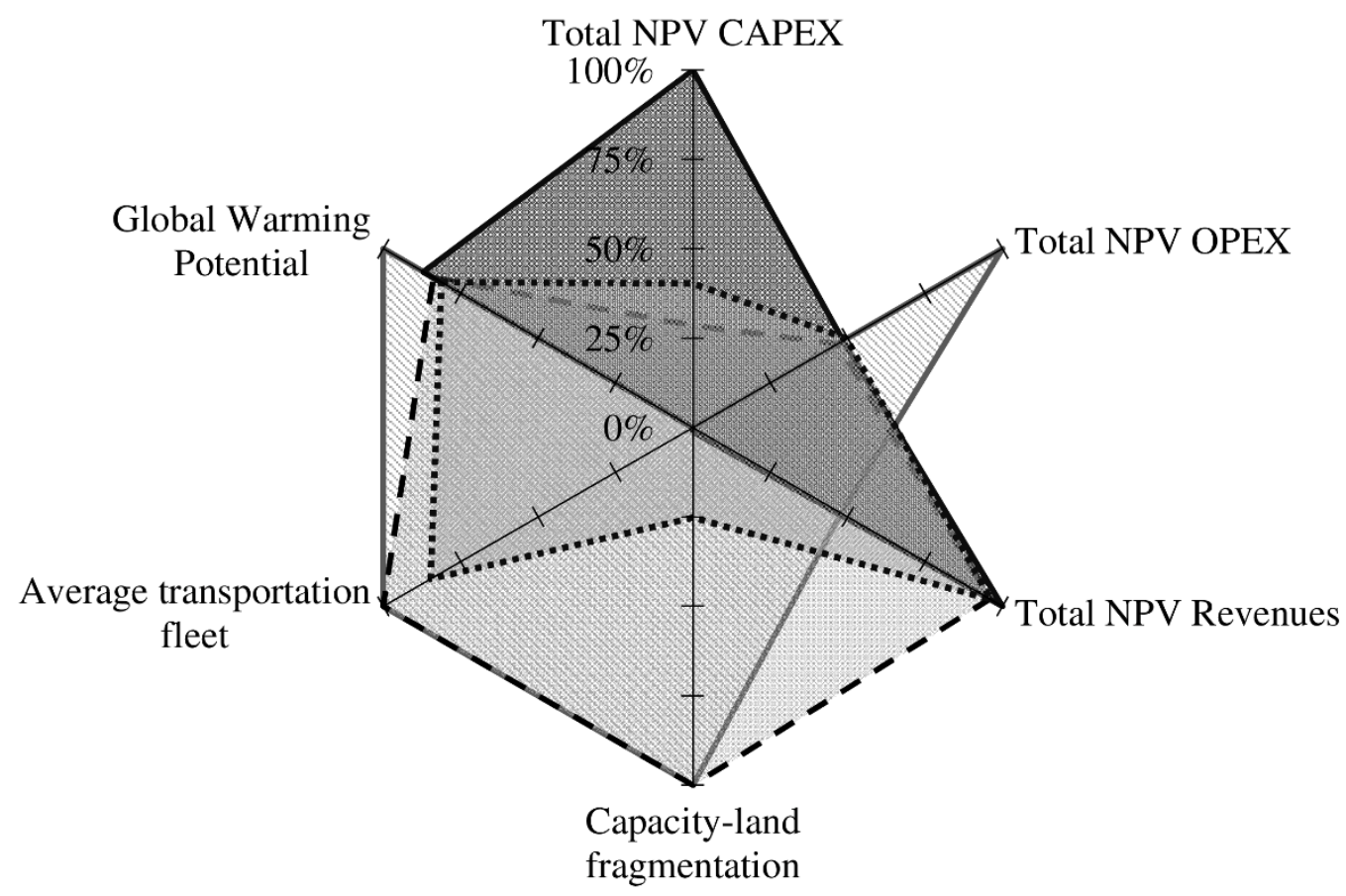

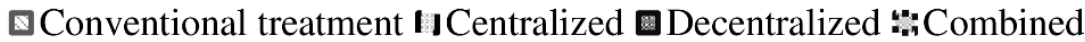

Figure 15. MSW management strategies comparison.

Although a decentralized WtEMS achieves the least capacity-land fragmentation, the combined WtEMS allows an important decrease in capacity-land fragmentation. The capacityland fragmentation was reduced by $74.8 \%$ in comparison with centralized and conventional waste treatment strategies. In addition, the combined WtEMS relieved the need for transportation by reducing the number of fleet by $15.3 \%$ in comparison with centralized and conventional systems. Figure 15 shows some of these tradeoffs graphically.

Although the results above were obtained for a realistic case study, the authors wish to highlight that these are not practical recommendations for waste treatment system deployment in Singapore. Such applied recommendations must be defined with strong implication of government authorities.

\section{Conclusions and further contributions}

The paper proposed a novel integrated decision-support methodology (DSM) for waste-toenergy management system (WtEMS) development in an urban environment. It made an important advancement toward segregation of MSW sources and modelling of their distributions across large urban territories. It proposed a WtEMS design optimization methodology accounting for multi-level candidate locations (e.g., at building, district, and global city levels) for facilities combining various treatment technologies of different capacities. The proposed methodology provides the optimization schedule for waste treatment capacity deployment over a large planning horizon together with optimal waste allocation schedule for different time periods. It provides a multi-criteria evaluation framework helping 
to assess optimal WtEMS design using not only economic criteria, but also environmental and social aspects important for urban planning.

The proposed DSM was tested using a case study for food waste management in Singapore using publicly available information and considering the deployment of a combined centralized-decentralized WtEMS. To identify a sustainable food waste management strategy, the promising technologies of micro- and large-scale AD were successfully tested under real urban conditions and have been considered for deployment. The scale effect for different installations was accounted for in two ways. On the one hand, the optimization methodology explicitly defines models for the decentralized (on-site) technologies of small capacities and the equivalent centralized (off-site) technologies of large treatment capacity. The economic and technical parameters for the technology were established based on the peculiarities of the real installations of different capacities ranges. On the other hand, the decrease in the installation cost with the increase of treatment unit capacities was accounted for through the economy of scale (EoS) for both decentralized and centralized facilities. The capacity utilization was indirectly accounted for in the objective function through the costs and revenues formulation. In this view, the optimization model naturally tends to maximize the capacity utilization of each installation in order to increase their revenues from electricity recovery and to avoid investments for new facilities deployment. The performance of the proposed combined WtEMS was compared with purely centralized, decentralized, and conventional MSM management strategies. The results show that the combined WtEMS reduced total operational expenses by about $50 \%$ and increased revenues from electricity recovery almost two-fold in comparison with conventional MSW management. It also allowed more optimal land use (i.e., capacity-land fragmentation was reduced by $74.8 \%$ ) and reduced the required transportation fleet by $15.3 \%$ in comparison with conventional MSW systems. The global warming potential (GWP) was improved by about $18.7 \%$.

Future developments were discussed around major topics related to MSW modelling, optimization of WtEMS deployment, and assessment. The design of cost-efficient and sustainable waste treatment infrastructure requires clear segregation of MSW into categories (e.g., food waste, paper/cardboard, horticultural waste, etc.), estimation of their generation amounts, and distribution across large urban territories. The MSW generation depends on various demographic and economic variables. Moreover, MSW amounts, categories, and generation schedules in different urban subzones can be influenced by various factors, e.g., social attractiveness of urban subzones. A possible axis for future research will be devoted to the development of an explicit MSW generation meta-model by connecting MSW categories with specific demographic and economic variables. Following the analysis in Section 28, different urban development indicators, e.g., centrality index, can be explored for MSW distribution modelling.

The preselection of MSW treatment technologies to be considered for possible deployment by WTEDM is crucial. This choice is highly dependent on the properties and composition of waste, economic parameters, treatment and resource recovery efficiency, and environmental factors. As per usual practice, the decisions regarding deployed technologies are guided not only by the facilities' CAPEX and OPEX, but also by the amounts of consumed and generated 
resources and their respective costs. In addition, the importance of other performance criteria, analyzed in Section 36, could significantly rise in future decades and require careful consideration for WtEMS design. To provide an adequate decision-support tool, an optimization methodology must enable realistic modelling of environmental and operational factors, but also of related uncertainties. The integration of uncertainties in the operational and environmental conditions will require further development and integration with the proposed optimization methodology. This can be considered by integrating the current deterministic optimization model with data-driven real options analysis, supporting flexible and adaptable deployment strategies in the face of uncertainty [59], [60]. Moreover, different decision rules can be tied with different uncertainty conditions to trigger different deployment options, i.e., system expansion with amounts of waste generation, technological shift with advancements in technology development, and system reconfiguration with changes in resources prices. This will allow integrating emerging technologies with more attractive economic, technical, and environmental performance into the MSW treatment deployment schedule, as well as accounting for treatment plant deterioration and decommissioning.

The paper provides deployment results for a combined centralized-decentralized WtEMS and analyzes the main advantages of this strategy. Optimal results show that the proportion of CF and DF deployment under EoS $=0.8$ represents $84.32 \%$ and $15.68 \%$, respectively. However, possible conversion of non-economic criteria, evaluated in Section 36, into additional objective functions for the multi-objective optimization can change the CF/DF proportion. The WtEMS deployment optimization based not only on economic, but also on environmental (e.g., GWP) and operational (e.g., fleet size and land use) objectives, could lead to an increase in installed capacity at decentralized candidate sites. In this view, future work can be related to the exploration of optimal equilibrium between $\mathrm{CF}$ and DF under different optimization objectives. Under current incentives for high recycling rates, the major factor selecting appropriate type of waste treatment technology remains the type of MSW sources. Indeed, to ensure coverage of the major recycling pathways, the appropriate technology must be identified for each MSW source. Furthermore, to improve the recycling outcomes, different symbiotic cross-relations (i.e., closed material loops) can be considered between major pathways when the resource recovered from treatment of one WMS source can be used in another MSW source technology or urban activity [61]. In this view, DF enables treating MSW locally and closer to final consumers of the recovered resources. However, urban symbiosis brings not only opportunities but also bottlenecks. One of them is that it requires involvement from various stakeholders possibly holding conflicting objectives, which makes the overall decision-making process less straightforward and more complex [16]. In this view, other techniques like graph theory [62] or agent-based modelling [63] may be required to model complex decisions in a multistakeholder setting.

However, under current incentives for high recycling rates the major factor for this selection remains number and type of MSW sources identified in the territory. Indeed, to ensure the major recycling pathways, the appropriate technology must be identified for each MSW source. Further, to improve recycling outcomes, different symbiotic cross-relations can be considered between major pathways when the resource recovered from treatment of one WMS source can be used in another MSW source technology or urban activity [61]. This joins the above 
conclusion on the need of deeper exploration of urban symbiotic relations applied to MSW treatment.

The integration of decentralized technologies into an urban environment leads to reconsideration of urban planning strategies and the increased importance of social cohesion and acceptance [64]. To ensure the sustainability of WtEMS, a proper design approach integrate different perspectives, including environmental and social considerations [65]. In this view, one of the future developments relates to the expansion of the multi-criteria assessment framework in order to include indicators related to social safety. Despite the attempt of [30] to address social risk issues, the proposed methodology still contains some bottlenecks (e.g., equal weighting factors to economic and risk objectives that made the cost dominant and social risk effect approaching zero in the decision framework). In this view, the consideration of social factors requires an appropriate analysis before a more adequate evaluation framework can be proposed.

A more detailed analysis of the empirical deployment strategy and on field diagnostic test can be done through the application of the developed DSM for an MSW management pilot project. Such a pilot project, selected to play the role of the representative urban context on the restricted territory perimeter, enables simultaneous development, test, and implementation of the technological developments for waste treatment and data-driven decision-support methodologies. This work is foreseen for the next phase of the current research project.

\section{Acknowledgements}

This research is supported by the National Research Foundation and the Prime Minister's Office of Singapore under its Campus for Research Excellence and Technological Enterprise (CREATE) programme. The authors acknowledge the valuable inputs from Yeo Teck Kian on MSW modelling and Tong Huanhuan for sharing her expertise on waste treatment processes. The authors also wish to thank anonymous referees for their scrupulous review of the work and for the comments provided, which have helped improving the paper significantly. 


\section{Appendix A. Optimization model input}

Table A1. Overview of food waste treatment technologies.

\begin{tabular}{|c|c|c|c|c|c|c|c|c|c|}
\hline Technology & Category & Resource output & $\begin{array}{l}\text { Resource } \\
\text { requiremen } \\
\text { ts }\end{array}$ & Advantages & Capacity $^{(1)}$ & CAPEX & O\&M & Manpower & $\begin{array}{l}\text { Carbon } \\
\text { emissions }\end{array}$ \\
\hline $\begin{array}{l}\text { Waste-to- } \\
\text { Energy } \\
\text { Incineration } \\
\text { (Benchmark } \\
\text { ) [52] }\end{array}$ & $\begin{array}{l}\text { Thermal } \\
\text { processing }\end{array}$ & $\begin{array}{l}\text { Energy positive } \\
\text { Electricity } \sim 130 \\
\mathrm{kWh} / \text { ton } \\
\text { processed MSW; } \\
\text { Ashes } 15-20 \% \text { of } \\
\text { MSW by weight }\end{array}$ & $\begin{array}{l}\text { Electricity } \\
\sim \quad 70 \\
\text { kWh/ton of } \\
\text { processed } \\
\text { MSW [69] }\end{array}$ & $\begin{array}{l}\text { Suitable for energy } \\
\text { generation for urban usage, } \\
\text { close location to } \\
\text { municipalities facilitating } \\
\text { MSW transportation and } \\
\text { recovered electricity } \\
\text { supply }\end{array}$ & $\begin{array}{l}\text { Large } \\
\text { capacity: } \\
500-3,000 \\
\text { ton of MSW } \\
\text { per day } \\
150 \\
\text { tons/day }\end{array}$ & $\begin{array}{l} \\
\$ 650 / \text { ton } \\
\text { of annual } \\
\text { capacity } \\
35,6 \\
\text { M\$/unit }\end{array}$ & $\begin{array}{l}\text { Regular on-going } \\
\text { costs associated } \\
\text { with operation, } \\
\text { cleaning and ash } \\
\text { removal } \\
\$ 900,000 / \text { year per } \\
\text { unit }\end{array}$ & $\begin{array}{l}\text { Required trained } \\
\text { operating staff - } \\
\text { requires around } \\
50 \quad \text { staff to } \\
\text { operate } \\
\$ 900,000 / \text { year } \\
\text { per unit }\end{array}$ & $\begin{array}{l}5.93 \cdot 10^{5} \mathrm{~g} \\
\mathrm{CO}_{2} \\
\text { equivalent/t } \\
\text { on of treated } \\
\text { waste [69] }\end{array}$ \\
\hline $\begin{array}{l}\text { Wet/Dry } \\
\text { Anaerobic } \\
\text { Digestion } \\
\text { (AD) [52], } \\
{[66],[67]}\end{array}$ & $\begin{array}{l}\text { Biological } \\
\text { digestion }+ \\
\text { thermal } \\
\text { processing }\end{array}$ & 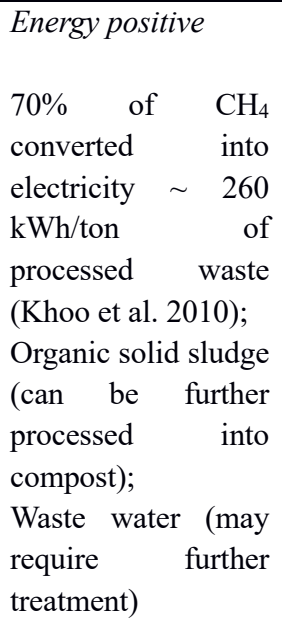 & $\begin{array}{l}\text { Electricity } \\
\sim \quad 32 \\
\text { kWh/ton of } \\
\text { processed } \\
\text { MSW [69] }\end{array}$ & $\begin{array}{l}\text { Qualified as a versatile and } \\
\text { adaptable to different } \\
\text { applications and sizes; } \\
\text { viable and economically } \\
\text { feasible technology for } \\
\text { large application }\end{array}$ & $\begin{array}{l}\text { Small and } \\
\text { medium } \\
\text { capacity }> \\
50 \text { ton of } \\
\text { MSW per } \\
\text { day }\end{array}$ & $\begin{array}{l}\sim \quad \$ 110- \\
150 / \text { ton of } \\
\text { annual } \\
\text { capacity } \\
1.08 \\
\text { M\$/unit }\end{array}$ & $\begin{array}{l}\text { Regular } \\
\text { maintenance } \\
\text { required on all } \\
\text { machines, costs } \\
\text { associated with } \\
\text { removal of } \\
\text { digested material } \\
\$ 360,000 / \text { year per } \\
\text { unit }\end{array}$ & $\begin{array}{l}\text { Large industrial } \\
\text { units } \\
\text { requires }>20 \\
\text { staff to operate } \\
\$ 360,000 / \text { year } \\
\text { per unit }\end{array}$ & $\begin{array}{l}0.2 \cdot 10^{5} \mathrm{~g} \\
\mathrm{CO}_{2} \\
\text { equivalent/t } \\
\text { on of treated } \\
\text { waste [69] }\end{array}$ \\
\hline $\begin{array}{l}\text { Micro-scale } \\
\text { Anaerobic } \\
\text { Digestion } \\
\text { [50], [68] }\end{array}$ & $\begin{array}{l}\text { Biological } \\
\text { digestion }+ \\
\text { thermal } \\
\text { processing }\end{array}$ & $\begin{array}{l}\text { Energy positive } \\
\text { Net electricity } \\
\text { output for the whole } \\
\text { site }-271 \mathrm{kWh} / \mathrm{ton}\end{array}$ & $\begin{array}{l}\text { Electricity } \\
\sim \quad 117 \\
\mathrm{kWh} / \text { ton } \\
\text { (without } \\
\text { considering } \\
\text { logging } \\
\text { system) }\end{array}$ & 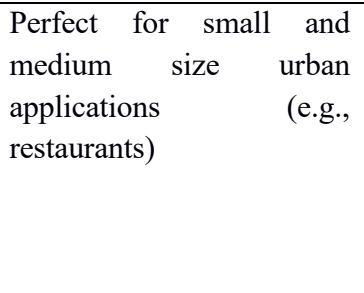 & $\begin{array}{l}\text { Small } \\
\text { capacity: }> \\
20 \\
\text { digester } \\
\text { equivalent } \\
\text { to about } 1 \\
\text { ton/day }\end{array}$ & $\begin{array}{l}\sim \\
\$ 345 / \text { ton } \\
\text { of annual } \\
\text { capacity } \\
0.125 \\
M \$ \text { unit }\end{array}$ & $\begin{array}{l}\text { Regular technical } \\
\text { servicing, removal } \\
\text { of residues } \\
\$ 4300 / \text { year per } \\
\text { unit }\end{array}$ & $\begin{array}{l}\text { Almost } \\
\text { automated } \\
\text { charging } \\
\text { \$4300/year per } \\
\text { unit }\end{array}$ & $\begin{array}{l}0.2 \cdot 10^{5} \mathrm{~g} \\
\mathrm{CO}_{2} \\
\text { equivalent/t } \\
\text { on of treated } \\
\text { waste [69] }\end{array}$ \\
\hline
\end{tabular}


(1) CF units capacities have been downscaled to fit with total food waste generation in WGS of Figure 9.

(2) Process emissions from (Khoo et al. 2010) have been converted into $\mathrm{CO}_{2}$ emissions equivalent to estimate their Global Warming Potential [70] (IPCC 2007). 


\section{References}

[1] UN, "World Urbanization Prospectives," United Nations, 2014.

[2] UN Habitat, "Urbanization and development. Emerging Futures," UN Habitat, 2016.

[3] D. Hoornweg and P. Bhada-Tata, "What a waste: A Global Review of Solid Waste Management," The World Bank, 2012.

[4] JESC, "History and Current State of Waste Management in Japan," 2014. [Online]. Available: https://www.env.go.jp/en/recycle/smcs/attach/hcswm.pdf.

[5] WMR, "South Korea Legislates Towards a Zero Waste Society," Waste Management Review, 2015. [Online]. Available: http://wastemanagementreview.com.au/southkorea-legislates-towards-a-zero-waste-society/. [Accessed: 26-Feb-2018].

[6] Greentumble, "Countries with the Most Sofisticated Waste Management," Greentumble, 2016. [Online]. Available: https:/greentumble.com/countries-withthe-most-sophisticated-waste-management/. [Accessed: 26-Feb-2018].

[7] N. Yukalang, B. Clarke, and K. Ross, "Barriers to Effective Municipal Solid Waste Management in a Rapidly Urbanizing Area in Thailand," Environ. Res. Public Heal., vol. 14, 2017.

[8] N. Ejaz, N. Akhtar, H. Nisar, and U. A. Naeem, "Environmental impacts of improper solid waste management in developing countries : a case study of Rawalpindi City," Trans. Ecol. Environ., vol. 142, pp. 379-387, 2010.

[9] UN, "Shanghai Manual - A Guide for Sustainable Urban Development of the 21st Century," Shanghai, China, 2011.

[10] V. Yadav, A. K. Bhurjee, S. Karmakar, and A. K. Dikshit, "A facility location model for municipal solid waste management system under uncertain environment," Sci. Total Environ., no. October 2016, pp. 1-12, 2017.

[11] J. Xiong, T. Sheng, A. Ng, and S. Wang, "An optimization model for economic feasibility analysis and design of decentralized waste-to-energy systems," Energy, vol. 101, pp. 239-251, 2016.

[12] Z. Wen, Y. Wang, and D. De Clercq, "What is the true value of food waste? A case study of technology integration in urban food waste treatment in Suzhou City, China," J. Clean. Prod., vol. 118, pp. 88-96, 2016. 
[13] Y. Wei, J. Li, D. Shi, G. Liu, Y. Zhao, and T. Shimaoka, "Environmental challenges impeding the composting of biodegradable municipal solid waste: A critical review," Resour. Conserv. Recycl., vol. 122, pp. 51-65, 2017.

[14] M. S. Korai, R. B. Mahar, and M. A. Uqaili, "The feasibility of municipal solid waste for energy generation and its existing management practices in Pakistan," Renew. Sustain. Energy Rev., vol. 72, no. December 2016, pp. 338-353, 2017.

[15] P. K. Halder, N. Paul, M. U. H. Joardder, and M. Sarker, "Energy scarcity and potential of renewable energy in Bangladesh," Renew. Sustain. Energy Rev., vol. 51, pp. 1636-1649, 2015.

[16] G. Kayakutlu, T. Daim, M. Kunt, A. Altay, and Y. Suharto, "Scenarios for regional waste management," Renew. Sustain. Energy Rev., vol. 74, no. April 2016, pp. 13231335, 2017.

[17] S. N. M. Menikpura, J. Sang-Arun, and M. Bengtsson, "Integrated Solid Waste Management: An approach for enhancing climate co-benefits through resource recovery," J. Clean. Prod., vol. 58, pp. 34-42, 2013.

[18] A. J. Morrissey and J. Browne, "Waste management models and their application to sustainable waste management," Waste Manag., vol. 24, pp. 297-308, 2004.

[19] A. Vitorino de Souza Melaré, S. Montenegro González, K. Faceli, and V. Casadei, "Technologies and decision support systems to aid solid-waste management: a systematic review," Waste Manag., vol. 59, pp. 567-584, 2017.

[20] M. Fitzgerald, "Data-driven City Management. A Close Look at Amsterdam's Smart City Initiative," MITSLoan Management Review, 2016. [Online]. Available: https://sloanreview.mit.edu/case-study/data-driven-city-management/. [Accessed: 28-Feb-2018].

[21] P. Bhunia, "S\$10.8 million Environmental Robotics Programme and Closing the Waste Loop research funding initiative from NEA Singapore," Open GovAsia, 2018. [Online]. Available: https://www.opengovasia.com/articles/s-10-8-millionenvironmental-robotics-programme-and-closing-the-waste-loop-research-fundinginitiative-from-nea-singapore. [Accessed: 27-Feb-2018].

[22] DIRECTIVE 2008/98/EC, "Waste and repealing certain directives." Brussels: The European Parliament and the Council., pp. 3-30, 2008.

[23] M. Abbasi and A. El Hanandeh, "Forecasting municipal solid waste generation using artificial intelligence modelling approaches.," Waste Manag., vol. 56, pp. 1322, 2016. 
[24] S. Keser, S. Duzgun, and A. Aksoy, "Application of spatial and non-spatial data analysis in determination of the factors that impact municipal solid waste generation rates in Turkey," Waste Manag., vol. 32, no. 3, pp. 359-371, 2012.

[25] Z. S. Li, H. Z. Fu, and X. Y. Qu, "Estimating municipal solid waste generation by different activities and various resident groups: A case study of Beijing," Sci. Total Environ., vol. 409, no. 20, pp. 4406-4414, 2011.

[26] S. Lebersorger and P. Beigl, "Municipal solid waste generation in municipalities: Quantifying impacts of household structure, commercial waste and domestic fuel," Waste Manag., vol. 31, no. 9-10, pp. 1907-1915, 2011.

[27] V. M. Adamovic, D. Z. Antanasijevic, M. Ristic, A. A. Peric-Grujic, and V. V. Pocajt, "Prediction of municipal solid waste generation using artificial neural network approach enhanced by structural break analysis," Environ. Sci. Pollut. Res., vol. 24, pp. $299-311,2017$.

[28] M. Chen, A. Giannis, and J.-Y. Wang, "Application of system dynamics model for municipal solid waste generation and lanfill capacity evaluaiton in Singapore," Macrotheme Rev., vol. 1, pp. 101-114, 2012.

[29] R. Minciardi, M. Paolucci, M. Robba, and R. Sacile, "Multi-objective optimization of solid waste flows: Environmentally sustainable strategies for municipalities," Waste Manag., vol. 28, no. 11, pp. 2202-2212, 2008.

[30] H. Yu, W. D. Solvang, and S. Yuan, "A Multi-objective Decision Support System for Simulation and Optimization of Municipal Solid Waste Management System," in 3rd IEEE International Conference on Cognitive Infocommunications, 2012, pp. 193-199.

[31] J. E. Santibanez-Aguilar, J. Martinez-Gomez, J. M. Ponce-Ortega, F. NapolesRevera, M. Serna-Gonzalez, J. B. Gonzalez-Campos, and M. M. El-Halwagi, "Optimal planning for the reuse of municipal solid waste considering economic, environmental, and safety objectives," Am. Inst. Chem. Eng. J., vol. 61, no. 6, pp. 1881-1899, 2015.

[32] A. Mirdar Harijani, S. Mansour, B. Karimi, and C.-G. Lee, "Multi-period sustainable and integrated recycling network for municipal solid waste - A case study in Tehran," J. Clean. Prod., vol. 151, pp. 96-108, 2017.

[33] C. K. M. Lee, C. L. Yeung, Z. R. Xiong, and S. H. Chung, "A mathematical model for municipal solid waste management - A case study in Hong Kong," Waste Manag., vol. 58, pp. 430-441, 2016. 
[34] A. A. Rentizelas, A. I. Tolis, and I. P. Tatsiopoulos, "Combined Municipal Solid Waste and biomass system optimization for district energy applications," Waste Manag., vol. 34, no. 1, pp. 36-48, 2014.

[35] C. Dai, Y. P. Li, and G. H. Huang, "A two-stage support-vector-regression optimization model for municipal solid waste management - A case study of Beijing, China," J. Environ. Manage., vol. 92, no. 12, pp. 3023-3037, 2011.

[36] P. Nilsson and T. H. Christensen, "Waste Collection: Systems and Organization," in Solid Waste Technology \& Management, T. H. Christensen, Ed. Blackwell Publishing Ltd., 2011, pp. 277-295.

[37] S. Goren and F. Ozdemir, "Regulation of waste and waste management in Turkey," Waste Manag. Res., vol. 29, no. 4, pp. 433-441, 2010.

[38] P. R. Jacobi and G. R. Besen, "Solid Waste Management in Sao Paulo: The challenges of sustainability," Estud. Avancados, vol. 25, no. 71, pp. 135-158, 2011.

[39] M. Kéita, "Building partnerships for urban waste management in Bamako," in "Making Decentralisation Work" programme (MDW), Drylands Programme, IIED, 2001, pp. 1-21.

[40] F. Ivis, "Calculating Geographic Distance: Concepts and Methods," in NEGUS, 2006, pp. 1-10.

[41] J. Haldi and D. Whitcomb, "Economies of Scale in Industrial Plants," J. Polit. Econ., vol. 75, no. 4, pp. 373-385, 1967.

[42] WEF, "The New Plastics Economy Rethinking the future of plastics," Cologny/Geneva Switzerland, 2016.

[43] B. Mahadevan, Operations Management: Theory and Practice, vol. 1, no. 1. 2007.

[44] M. Ichimura, "Urbanization, Urban Environment and Land Use : Challenges and Opportunities An Issue Paper," no. January, pp. 1-14, 2003.

[45] D. Demetriou, "Chapter 2. Land Fragmentation," in The Development of an Integrated Planning and Decision Support System (IPDSS) for Land Consolidation, 2014, pp. 1-340.

[46] URA, "Concept Palan 2011 and MND's Land Use Plan," Urban Development Auhtority, 2013. [Online]. Available: https://www.ura.gov.sg/uol/conceptplan.aspx?p1=View-Concept-Plan\&p2=Land-Use-Plan-2013. [Accessed: 10-Mar2017]. 
[47] NEA, "Waste statistics and overall recycling," 2016. [Online]. Available: http://www.nea.gov.sg/energy-waste/waste-management/waste-statistics-andoverall-recycling. [Accessed: 14-Feb-2017].

[48] C. Zhong, M. Schla, S. Mu, M. Batty, and G. Schmitt, "Revealing centrality in the spatial structure of cities from human activity patterns," Urban Stud., vol. 54, no. 2, pp. 437-455, 2017.

[49] R. Chainey, "Which countries waste the most food?," World Economic Forum, 2015. [Online]. Available: https://www.weforum.org/agenda/2015/08/which-countrieswaste-the-most-food/. [Accessed: 02-Aug-2017].

[50] M. Walker, H. Theaker, R. Yaman, D. Poggio, W. Nimmo, A. Bywater, G. Blanch, and M. Pourkashanian, "Assessment of micro-scale anaerobic digestion for management of urban organic waste : A case study in London, UK," Elsevier Ltd, 2017.

[51] Izabelanair, "Giant LEAP for micro-scale AD," Food Science and Technology, 2017. [Online]. Available: http://www.fstjournal.org/features/31-3/micro-scale-ad. [Accessed: 01-Mar-2018].

[52] P. R. M. Cook, "An Analysis of New and Emerging Food Waste Recycling Technologies and Opportunities for Application,” New York, USA, 2014.

[53] JTC, “Land for General Industries," 2016. [Online]. Available: http://www.jtc.gov.sg/industrial-land-and-space/pages/land-for-generalindustries.aspx. [Accessed: 18-Nov-2016].

[54] L. Lam, "Singapore Budget 2017: Singapore to implement carbon tax from 2019; diesel taxes restructured," The Straits Times, 2017. [Online]. Available: http://www.straitstimes.com/singapore/environment/singapore-budget-2017singapore-to-implement-carbon-tax-from-2019-2-vehicle. [Accessed: 07-Aug2018].

[55] F. Dunnebeil and U. Lambrecht, "Fuel efficiency and emissions of trucks in Germany. An overview," 2012.

[56] EMA, "Electricity Tarifs Singapore," 2017. [Online]. Available: https://www.ema.gov.sg/Residential_Electricity_Tariffs.aspx. [Accessed: 27-Jun2017].

[57] A. S. Manne, Investments for Capacity Expansion: Size, Location, and TimePhasing. MIT Press, Cambridge, MA (USA), 1967. 
[58] H. Tong and Y.-W. Tong, "Life cycle assessment of Food Waste Management Options in Singapore," in 15th International Conference on Sustainable Energy Technologies 19 - 22 of July, 2016.

[59] M. Cardin, Q. Xie, T. S. Ng, S. Wang, and J. Hu, "An approach for analyzing and managing flexibility in engineering systems design based on decision rules and multistage stochastic programming," IISE, vol. 49, no. 1, pp. 1-12, 2017.

[60] A. M. Caunhye and M. Cardin, "An Approach based on Robust Optimization and Decision Rules for Analyzing Real Options in Engineering Systems Design," Accept. Publ. IISE Trans., pp. 1-43, 2017.

[61] Y. Geng, F. Tsuyoshi, and X. Chen, "Evaluation of innovative municipal solid waste management through urban symbiosis : a case study of Kawasaki q," J. Clean. Prod., vol. 18, pp. 993-1000, 2010.

[62] Y. Melese, P. Heijnen, R. Stikkelman, and P. Herder, "International Journal of Greenhouse Gas Control An approach for $\mathrm{fl}$ exible design of infrastructure networks via a risk sharing contract : The case of $\mathrm{CO} 2$ transport infrastructure," Int. J. Greenh. Gas Control, vol. 63, no. March, pp. 401-411, 2017.

[63] Z. He, J. Xiong, T. Sheng, B. Fan, and C. A. Shoemaker, "Managing competitive municipal solid waste treatment systems : An agent-based approach," Eur. J. Oper. Res., vol. 263, no. 3, pp. 1063-1077, 2017.

[64] A. M. Adil and Y. Ko, "Socio-technical evolution of Decentralized Energy Systems: A critical review and implications for urban planning and policy," Renew. Sustain. Energy Rev., vol. 57, pp. 1025-1037, 2016.

[65] Y. T. Chong, K. M. Teo, and L. C. Tang, "A lifecycle-based sustainability indicator framework for waste-to-energy systems and a proposed metric of sustainability," Renew. Sustain. Energy Rev., vol. 56, pp. 797-809, 2016.

[66] D. Sanscartier, H. L. Maclean, and B. Saville, "Electricity Production from Anaerobic Digestion of Household Organic Waste in Ontario: Techno-Economic and GHG Emission Analyses,” Environ. Sci. Technol., vol. 46, pp. 1233-1242, 2012.

[67] H. Leffertstra, "Anaerobic Digestion - turning organic waste into energy and fertilizer," Zaragoza, Spain, 2003.

[68] R. Yaman, A. Bywater, J. Murcott, G. Blanch, D. Neylan, D. Poggio, M. Walker, C. Andrews, and C. Kibber, "Optimising Urban Micro AD Networks," Banbury, UK, 2013. 
[69] H. H. Khoo, T. Z. Lim, and R. B. H. Tan, "Food waste conversion options in Singapore: Environmental impacts based on an LCA perspective," Sci. Total Environ., vol. 408, no. 6, pp. 1367-1373, 2010.

[70] IPCC, "Direct Global Warming Potentials," Intergovernmental Panel on Climate Change, 2007.2 AOnline]. Available: https://www.ipcc.ch/publications_and_data/ar4/wg1/en/ch2s2-10-2.html. [Accessed: 07Aug-2017]. 